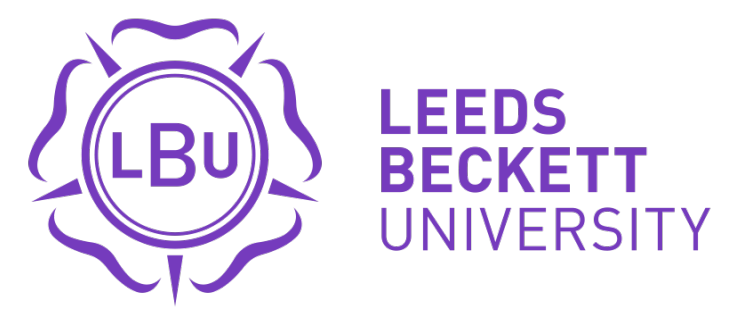

Citation:

Alaka, HA and Oyedele, LO and Owolabi, HA and Kumar, V and Ajayi, SO and Akinade, OO and Bilal, M (2017) Systematic Review of Bankruptcy Prediction Models: Towards A Framework for Tool Selection. Expert Systems with Applications. ISSN 0957-4174 DOI: https://doi.org/10.1016/j.eswa.2017.10.040

Link to Leeds Beckett Repository record:

https://eprints.leedsbeckett.ac.uk/id/eprint/4197/

Document Version:

Article (Accepted Version)

The aim of the Leeds Beckett Repository is to provide open access to our research, as required by funder policies and permitted by publishers and copyright law.

The Leeds Beckett repository holds a wide range of publications, each of which has been checked for copyright and the relevant embargo period has been applied by the Research Services team.

We operate on a standard take-down policy. If you are the author or publisher of an output and you would like it removed from the repository, please contact us and we will investigate on a case-by-case basis.

Each thesis in the repository has been cleared where necessary by the author for third party copyright. If you would like a thesis to be removed from the repository or believe there is an issue with copyright, please contact us on openaccess@leedsbeckett.ac.uk and we will investigate on a case-by-case basis. 


\section{Systematic Review of Bankruptcy Prediction Models: Towards A Framework for Tool Selection}

Hafiz A. Alaka ${ }^{1}$, Lukumon O. Oyedele ${ }^{2}$, Hakeem A. Owolabi ${ }^{3}$, Vikas Kumar ${ }^{4}$, Saheed O. Ajayi ${ }^{5}$, and Olugbenga O. Akinade ${ }^{6}$, Muhammad Bilal ${ }^{7}$

${ }^{1}$ Senior Lecturer, Faculty of Engineering, Environment and Computing, Coventry University, Coventry, United Kingdom. hafizalaka@gmail.com

${ }^{2}$ Professor, Bristol Enterprise Research and Innovation Centre (BERIC), University of the West of England, Bristol, United Kingdom. L.Oyedele@uwe.ac.uk

${ }^{3}$ Lecturer, Department of International Strategy \& Business, The University of Northampton, United Kingdom. hakeem.owolabi@northampton.ac.uk

${ }^{4}$ Professor, Bristol Enterprise Research and Innovation Centre (BERIC), University of the West of England, Bristol, United Kingdom. Vikas.Kumar@uwe.ac.uk

${ }^{5}$ Senior Lecturer, School of Built Environment and Engineering, Leeds Becket University, Leeds, United Kingdom.s.ajayi@leedsbeckett.ac.uk

${ }^{6}$ Research Fellow, Bristol Enterprise Research and Innovation Centre (BERIC), University of the West of England, Bristol, United Kingdom. olugbenga2.akinade@live.uwe.ac.uk

${ }^{7}$ Research Fellow, Bristol Enterprise Research and Innovation Centre (BERIC), University of the West of England, Bristol, United Kingdom. muhammad.bilal@uwe.ac.uk 


\begin{abstract}
The bankruptcy prediction research domain continues to evolve with many new different predictive models developed using various tools. Yet many of the tools are used with the wrong data conditions or for the wrong situation. Using the Web of Science, Business Source Complete and Engineering Village databases, a systematic review of 49 journal articles published between 2010 and 2015 was carried out. This review shows how eight popular and promising tools perform based on 13 key criteria within the bankruptcy prediction models research area. These tools include two statistical tools: multiple discriminant analysis and Logistic regression; and six artificial intelligence tools: artificial neural network, support vector machines, rough sets, case based reasoning, decision tree and genetic algorithm. The 13 criteria identified include accuracy, result transparency, fully deterministic output, data size capability, data dispersion, variable selection method required, variable types applicable, and more. Overall, it was found that no single tool is predominantly better than other tools in relation to the 13 identified criteria. A tabular and a diagrammatic framework are provided as guidelines for the selection of tools that best fit different situations. It is concluded that an overall better performance model can only be found by informed integration of tools to form a hybrid model. This paper contributes towards a thorough understanding of the features of the tools used to develop bankruptcy prediction models and their related shortcomings.
\end{abstract}

Keywords: Bankruptcy prediction tools; Financial ratios; Error types; systematic review; tool selection framework; artificial intelligence tools, statistical tools. 


\subsection{Introduction}

The effect of high rate of business failure can be devastating to firm owner, partners, society and the country's economy at large (Edum-Fotwe et al., 1996; Xu and Zhang, 2009; Hafiz et al., 2015; Alaka et al., 2015). The consequent extensive research into developing bankruptcy prediction models (BPM) for firms is undoubtedly justified. The performance of such models is largely dependent on, among other factors, the choice of tool selected to build it. Apart from a few studies (e.g. Altman, 1968; Ohlson, 1980), tool selection in many BPM studies is not based on capabilities of the tool; rather it is either chosen based on popularity (e.g. Langford et al., 1993; Abidali and Harris, 1995; Koyuncugil and Ozgulbas, 2012) or based on professional background (e.g. Altman et al., 1994; Nasir et al., 2000; Lin and Mcclean, 2001; Hillegeist et al., 2004; Beaver et al., 2005). This is because there is no evaluation material which shows and compares the relative performance of major tools in relation to the many important criteria a BPM should satisfy. Such material can provide a guideline and subsequently aid an informed and justified tool selection for BPM developers.

Most prediction tools are either statistical or artificial intelligence (AI) based (Jo and Han, 1996; Balcaen and Ooghe, 2006). The most common statistical tool is the multiple discriminant analysis (MDA) which was first used by Altman (1968) to develop a BPM popularly known as Z model, based on Beaver's (1966) recommendation in his univariate work. MDA, normally used with financial ratios (quantitative variables), subsequently became popular with accounting and finance literature (Taffler, 1982) and many subsequent studies by finance professionals simply adopted MDA without considering the assumptions that are to be satisfied for MDA's model to be valid. This resulted in inappropriate application, causing developed models to be un-generalizable (Joy and Tollefson, 1975; Richardson and Davidson, 1984; Zavgren, 1985). Abidali and Harris (1995), for example, unscholarly employed A-score alongside Z-score (i.e. MDA) in order to involve qualitative managerial variables, alongside quantitative variables, in their analysis when logistic regression (LR) [or logit analysis] can handle both types of variables singularly.

AI tools are computer based techniques of which Artificial Neural Network (ANN or NN) is the most common for bankruptcy prediction (Aziz and Dar, 2006; Tseng and Hu, 2010). Simply because it is the most popular architecture, many studies arbitrarily employed the back-propagation algorithm of ANN for bankruptcy prediction (e.g. Odom and Sharda, 1990; Tam and Kiang, 1992; Wilson and Sharda, 1994; Boritz et al., 1995; among others) despite it having a number of relatively undesirable features which include computational intensity, absence of formal theory, "illogical network behaviour in response to different variations of the input values" etc. (Coats and Fant, 1993; Altman et al., 1994, p. 507; Zhang et al., 1999). Further, Fletcher and Goss (1993) developed an ANN prediction model for a relatively small sample size when ANNs are known to need large samples for optimal performance (Boritz et al., 1995; Shin et al., 2005; Ravi Kumar and Ravi, 2007).

These improper uses of tools regularly occur because there is no readily available evaluation material or guidelines which can help BPM developers identify which tool best suits what data/purpose/situation. As Chung et al. (2008, 
p. 20) put it, "given the variety of techniques now available for insolvency prediction, it is not only necessary to understand the uses and strengths of any prediction model, but to understand their limitations as well". Hence to ensure a BPM performs well with regards to criteria of preference (e.g. accuracy, type I error, transparency, among others), a model developer has to understand the strength and limitations of the available tools/techniques. This will ensure that the right tool is employed for the right data characteristics, right situation and the right purpose. This study thus aims to develop a comprehensive evaluation framework for selection of BPM tools using a systematic and comprehensive review. The following objectives are needed to achieve this aim:

1. Presentation of an overview of the common tools used for bankruptcy prediction and identification of BPM studies that have used these tools

2. Identifying the key criteria BPMs need to satisfy and how each tool performs in relation to each criterion by analysing the systematic review

The scope of this study is limited to reviewing only popular and promising tools that have been employed for the development of BPMs in past studies since interest in them is high. This is because it is virtually impossible to review all the many tools that can be used for this purpose in this study. In total, two statistical and six AI tools were reviewed. The next section explains the systematic review methodology used in this study with all the inclusion and exclusion criteria. This is followed by a brief description of each of the eight tools. Section four presents the 13 identified key criteria used to assess the tools. Section five discusses the analysis and results of the review in form of tables and charts. Section six presents the proposed tabular and diagrammatic frameworks. This is followed up with a conclusion section.

\subsection{Methodology}

This study used a systematic review method to create a guideline for the selection of an appropriate tool for developing a bankruptcy prediction model (BPM). There are so many tools that can be used to develop a BPM that it is virtually impossible to review them all in one study. As a result, the two most popular statistical tools as noted by Balcaen and Ooghe (2006) in their comprehensive review of BPMs were reviewed: multiple discriminant analysis (MDA) and Logistic regression (LR). Also covered in this review are the most popular and promising artificial intelligence (AI) tools as advocated by Aziz and Dar (2006) in their comprehensive review, and Min et al. (2006) among others: artificial neural network (ANN), support vector machines (SVM), rough sets (RS), case based reasoning (CBR), decision tree (DT) and genetic algorithm (GA). A process flow of the methodology is presented in Figure 1.

Systematic review is a well-known method for producing valid and reliable knowledge as it minimizes bias hence its popularity in the all-important medical research world (Tranfield et al., 2003; Schlosser, 2007). The inclusion criteria for this study were carefully chosen to allow fair comparison and ensure adequate quality (Khan et al., 
2003). To improve validity of this study, only peer reviewed journal articles were considered since they are considered to be of high quality and their contribution considered as very valid (Schlosser, 2007).

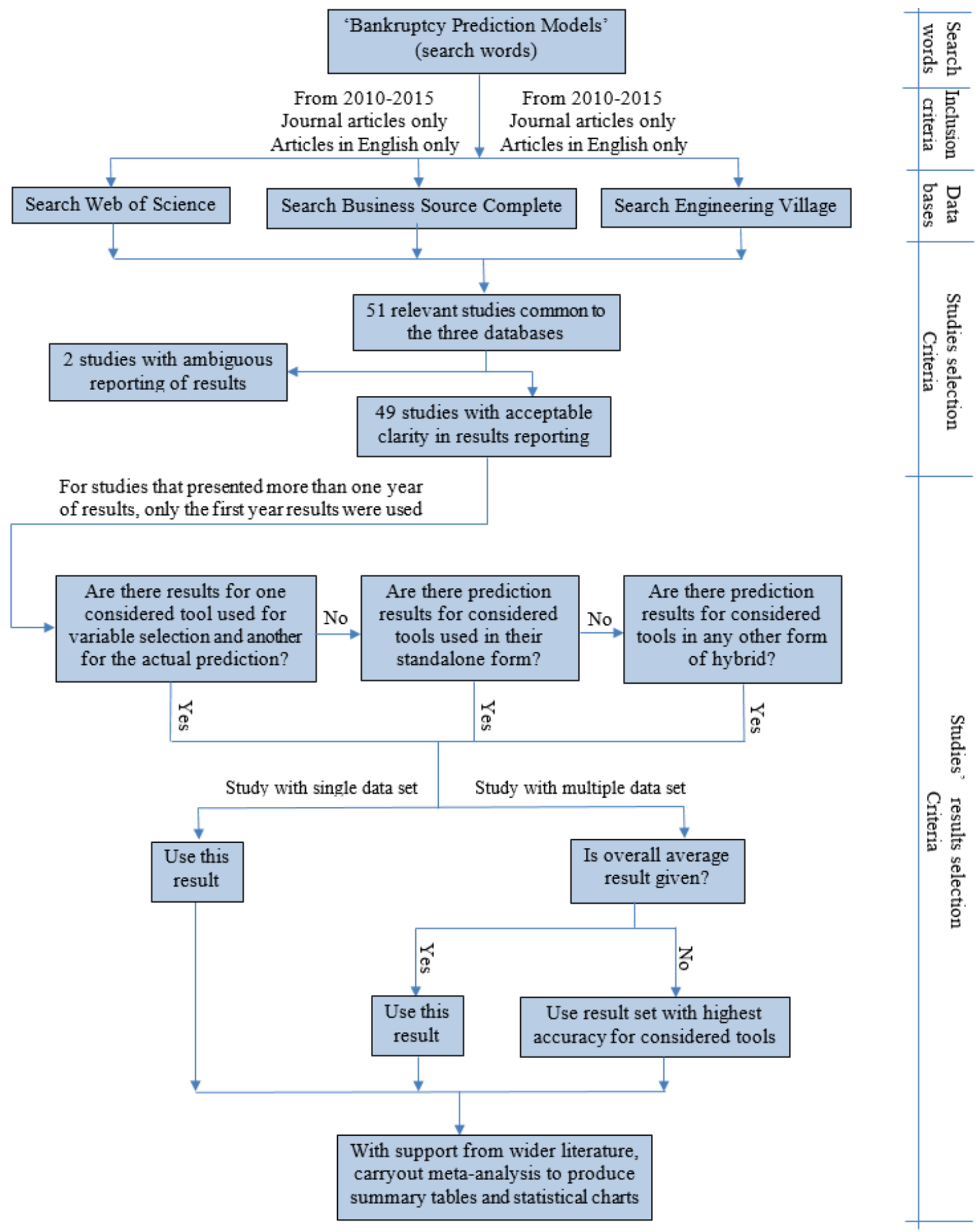

Figure 1: Process flow of the methodology (the term 'considered tool' refers to the eight tools considered in this study).

Systematic review requires wide literature search (Smith et al., 2011) hence following Appiah et al. (2015) approach, which is the most recently published systematic review in the BPM research area, the following 
databases were considered: Google Scholar; Wiley Interscience; Science Direct; Web of Science UK (WoS); and Business Source Complete (BSC). However, a careful observation revealed Google scholar produced an almost endless result and did not have the required filters to make it very efficient hence it was removed as it was unmanageable. Further observation revealed that (WoS) and BSC contained all the journal articles provided in Wiley and Science Direct; this is probably because the latter two are publishers while the former two are databases with articles from various publishers including the latter two. To increase the width of the search, Engineering Village (EV) database was added to WoS and BSC databases to perform the final search. EV was chosen because articles from the engineering world usually deal with BPM tools comprehensively.

The initial searches in the three databases (WoS, BSC and EV) showed that studies tend to use bankruptcy, insolvency and financial distress as synonyms for failure of firms. A search framework which captured all these words was thus designed with the following defined string ("Forecasting" OR "Prediction" OR "Predicting") AND ("Bankruptcy” OR “Insolvency” OR "Distress" OR "Default” OR "Failure”).

To ensure high consistency and repeatability of this study, and consequently reliability and quality (Stenbacka, 2001; Trochim and Donnelly, 2006), only studies that appeared in the three databases were used; this ensured the eradication of database bias (Schlosser, 2007). These databases contain studies from all over the world hence geographic bias was also eliminated. Balcaen and Ooghe (2006) in their comprehensive review of statistical tools in 2006 noted that AI tools, mainly ANN, were gradually becoming adopted in BPM studies. With new tools emerging all the time, a four-year advance from 2006, which would have seen more use of AI tools, is how a start year of 2010 was chosen for this study. The end year is the year this paper was written, 2015.

Generally, the topic of articles that emerge from the search looked okay to determine which ones were fit for this study. However, this was not the case for all articles. Where otherwise, article's abstract was read and, if necessary, introduction and/or conclusion were read. In some cases, the complete articles had to be read. Although language constraint is not encouraged in systematic review, it is sometimes unavoidable due to lack of funds to pay for interpretation services (Smith et al., 2011) as in the case of this study. Only studies written in English were thus used.

After eliminating unrelated studies that dealt with topics like credit scoring (e.g. Martens et al., 2010), policy forecasting (e.g. Won et al., 2012), or that did not use any of the tools reviewed (e.g. Martin et al., 2011), only 51 studies had a presence in the three data bases. Of these, two had great ambiguity in reporting their results hence were excluded, leaving 49 studies to be used as the sample. The 'review studies' in the search results (e.g. Sun et al., 2014) were not considered since original results from tools implementation were needed.

In the final 49 studies sample (i.e. the primary studies used for this systematic review), where results of tools in their hybrid forms and the result of the tools in their standalone form were presented, results of the tools in their standalone form was used to allow fair comparisons of inter-study results. However, where any of the eight tools 
in consideration is used for variable selection and in turn used to hybridise the predicting tool, the result of such hybrid is used. Where the tools were used on more than one dataset and the results of each dataset was presented alongside the total average from all dataset, the total average results were used. In cases where average values were not given, the result set with the best accuracy for most/all of the tools in consideration in this study was used so as to give all tools a good chance of high accuracy. In cases where the results of more than a year of prediction were given, the results of the first year were used to allow for fair comparison since most BPM studies normally present first year results.

As required for systematic review, a meta-analysis was done with data synthesised using 'summary of findings' tables, statistical methods and charts (Khan et al., 2003; Higgins, 2008; Smith et al., 2011); with facts explained sometimes by employing quotes from especially the reviewed studies, and discussions backed up with a wider review of literature. Three summary of findings tables were provided in this study. Where there is not enough information from the reviewed studies regarding a certain criterion, results are discussed using the reviewed studies and wider literature. Opinions are only taken as facts in such cases if there are no opposing studies. This type of deviation from protocol for a valid reason is acceptable in systematic review (Schlosser, 2007). Finally, this review is used to create a guideline using a tabular framework for tool comparisons and a diagrammatic framework that clearly shows what situations/data characteristics/variable types etc. each discussed tool is best suited to. This will ensure developers can choose a tool based on what they have and/or intend to get rather than just arbitrarily.

\subsection{The Tools}

This study will review eight tools used to develop bankruptcy prediction models including: multiple discriminant analysis (MDA), Logistic regression (LR), artificial neural network (ANN), support vector machines (SVM), rough sets (RS), case based reasoning (CBR), decision tree (DT) and genetic algorithm (GA).

Multiple Discriminant Analysis: MDA uses a linear combo of variables, normally financial ratios, that best differentiate between failing and surviving firms to classify firms into one of the two groups. The MDA function, constructed usually after variable selection, is as follows:

$\mathrm{Z}=\mathrm{c}_{1} \mathrm{X} 1+\mathrm{c}_{2} \mathrm{X} 2+\ldots \ldots \ldots \ldots+\mathrm{c}_{\mathrm{n}} \mathrm{Xn}$.

Where $\mathrm{c}_{1}, \mathrm{c}_{2}, \ldots \ldots \ldots \mathrm{c}_{\mathrm{n}},=$ discriminant coefficients; and $\mathrm{X} 1, \mathrm{X} 2, \ldots \ldots . \mathrm{Xn}=$ independent variables

MDA calculates the discriminant coefficients. The function is used to calculate a Z-score. A cut-off Z score is chosen based on status of sample firms

Logistic regression: LR is a "conditional probability model which uses the non-linear maximum log-likelihood technique to estimate the probability of firm failure under the assumption of a logistic distribution" (Jackson and Wood, 2013, p. 190). The LR function, constructed after variable selection, is as follows: 
$P_{l}\left(V_{i}\right)=1 /\left[1+\exp -\left(b_{0}+b_{1} V_{i l}+b_{2} V_{i 2}+\ldots \ldots+b_{n} V_{i n}\right)\right]=1 /\left[1+\exp -\left(D_{i}\right)\right]$

where $P_{l}\left(V_{i}\right)=$ probability of failure given the vector of attributes; $V_{i} ; V_{i j}=$ value of attribute or variable $\mathrm{j}(\mathrm{j}=1$, $2, \ldots ., \mathrm{n})$ for firm $i ; \quad \mathrm{b}_{\mathrm{j}}=$ coefficient for attribute $j ; \quad \mathrm{b}_{0}=$ intercept $; \quad \mathrm{D}_{\mathrm{i}}=$ logit of firm $i$.

The dependent variable $P_{l}$ is expressed in binary form $(0,1)$ (Boritz and Kennedy, 1995).

Neural Network: ANN was created to imitate how the neural system of the human brain works (Hertz et al., 1991) and was first applied to bankruptcy prediction by Odom and Sharda (1990). A typical ANN is a network of nodes interconnected in layers. There are various parameters, architectures, algorithms, and training methods that can be used to develop an ANN (Jo and Han, 1996) and choosing the best combination can be demanding.

Support vector machines: SVM employs a linear model to develop an optimal separating hyperplane by using a highly non-linear mapping of input vectors into a high-dimensional feature space (Shin et al., 2005; Ravi Kumar and Ravi, 2007). It constructs the boundary using binary class. The variables closest to the hyperplane are called support vectors and are used to define the binary outcome (failing or non-failing) of assessed firms. All other samples are ignored and are not involved in deciding the binary class boundaries (Vapnik, 1998). Like ANN, it has some parameters that can be varied for it to perform optimally (Dreiseitl and Ohno-Machado 2002).

Rough Sets: RS theory, discovered by Pawlak (1982), assumes that there is some information associated with all objects (firms) of a given universe; information which is given by some attributes (variables) that can describe the objects. Objects that possess the same attributes are indiscernible (similar) with respect to the chosen attributes. RS creates a partition in the universe that separates objects with similar attributes into blocks (e.g. failing and nonfailing blocks) called elementary sets (Greco et al., 2001). Objects that fall on the boundary line cannot be classified because information about them is ambiguous. RS is used to extract the decision rules to solve classification problems (Ravi Kumar and Ravi, 2007; Greco et al., 2001).

Case Based Reasoning: CBR fundamentally differs from other tools in that it does not try to recognize pattern, rather it classifies a firm based on a sample firm that possess similar attribute values (Shin and Lee, 2002). It justifies its decision by presenting the used sample cases (firms) from its case library (Kolodner, 1993). It induces decision rules for classification.

Decision Tree: DT became an important machine learning tool after Quinlan (1986) developed iterative dichotomiser 3 (ID3). DT uses entropy to measure the discriminant power of samples' variables and subsequently recursively partitions (RPA) the set of data for the classification of firms (Quinlan, 1986). Quinlan (1993) later developed the advanced version called Classifier 4.5 (C4.5). DT induces the decision rules. The positions of the rules in the decision tree are usually determined using heuristics (Jeng et al., 1997). For example, if profitability was found to be more important than liquidity, it will be placed above, or evaluated before, liquidity. 
Genetic Algorithm: GA is a searching optimization technique that imitates the Darwin principle of evolution in solving nonlinear, non-convex problems (Ravi Kumar and Ravi, 2007). It is effective at locating the global minimum in a very large space. It differs from other tools in that it simultaneously searches multiple points, works with character springs and uses probabilistic and not deterministic rules. GA can extract decision rules from data which can be used for classifying firms. It is applied to selected variables in order to find a cut-off score for each variable (Shin and Lee, 2002).

\subsection{Important Criteria Required for Bankruptcy Prediction Model Tools}

To be considered effective, there are many criteria that can be required to be satisfied by a tool when it is used to develop a bankruptcy prediction model (BPM). The set of criteria required usually depend on the situation and intention of the BPM developer. For example, a financier or client may simply be interested in the accuracy of a model. The BPM needed simply needs to be able to predict if a firm is financially healthy (unhealthy) enough to be granted (refused) a loan or contract, hence a highly accurate tool/technique is needed. A firm owner on the other hand is interested in result transparency as much as accuracy because he needs to know where/what the firm is going/doing wrong in order to know where rescue efforts need to be focused on. In such a case, a tool with high accuracy as well as result transparency will be needed to build the required BPM

Different researchers have used different criteria to develop their BPMs, however after a thorough and comprehensive review of the primary studies and other studies in the area, 13 criteria were identified to be the most common and important. Example of other reviewed studies include Tam and Kiang, (1992); Haykin, (1994); Zurada et al., (1994); Edum-Fotwe et al., (1996); Dreiseitl and Ohno-Machado, (2002); Min and Lee, (2005); Shin et al., (2005); Balcaen and Ooghe, (2006); Ravi Kumar and Ravi, (2007); Chung et al., (2008); Ahn and Kim, (2009); to mention a few. The identified 13 criteria are as follows:

1) Accuracy: This relates to the percentage of firms a tool correctly classifies as failing or non-failing.

2) Result transparency: This has to do with interpretability of a tool's result.

3) Non-deterministic: The case where a tool cannot successfully classify a firm

4) Sample size: This refers to the sample size(s) suitable for a tool to perform optimally.

5) Data dispersion: This refers to ability of a tool to handle equally or unequally dispersed data

6) Variable selection: This refers to the variables selection methods required for optimum tool performance.

7) Multicollinearity: This refers to sensitivity of a tool to collinear variables.

8) Variable types: A tool's capability to analyse quantitative and/or qualitative variables.

9) Variable relationship: This explains a tool's limitation in analysing linear or non-linear variables

10) Assumptions imposed by tools: Requirements a sample data has to satisfy for a tool to perform optimally. 
11) Sample specificity/overfitting: This is when the model developed from a tool performs well on sample firms but badly on validation data.

12) Updatability: The ease with which a tool's model can be updated with new sample firms and its effectiveness afterwards

13) Integration capability: the ease with which a tool is hybridisable.

These 13 criteria can be grouped into three main categories as shown in Figure 2. These categories are:

1) Results related criteria

2) Data related criteria

3) Tool's properties related criteria

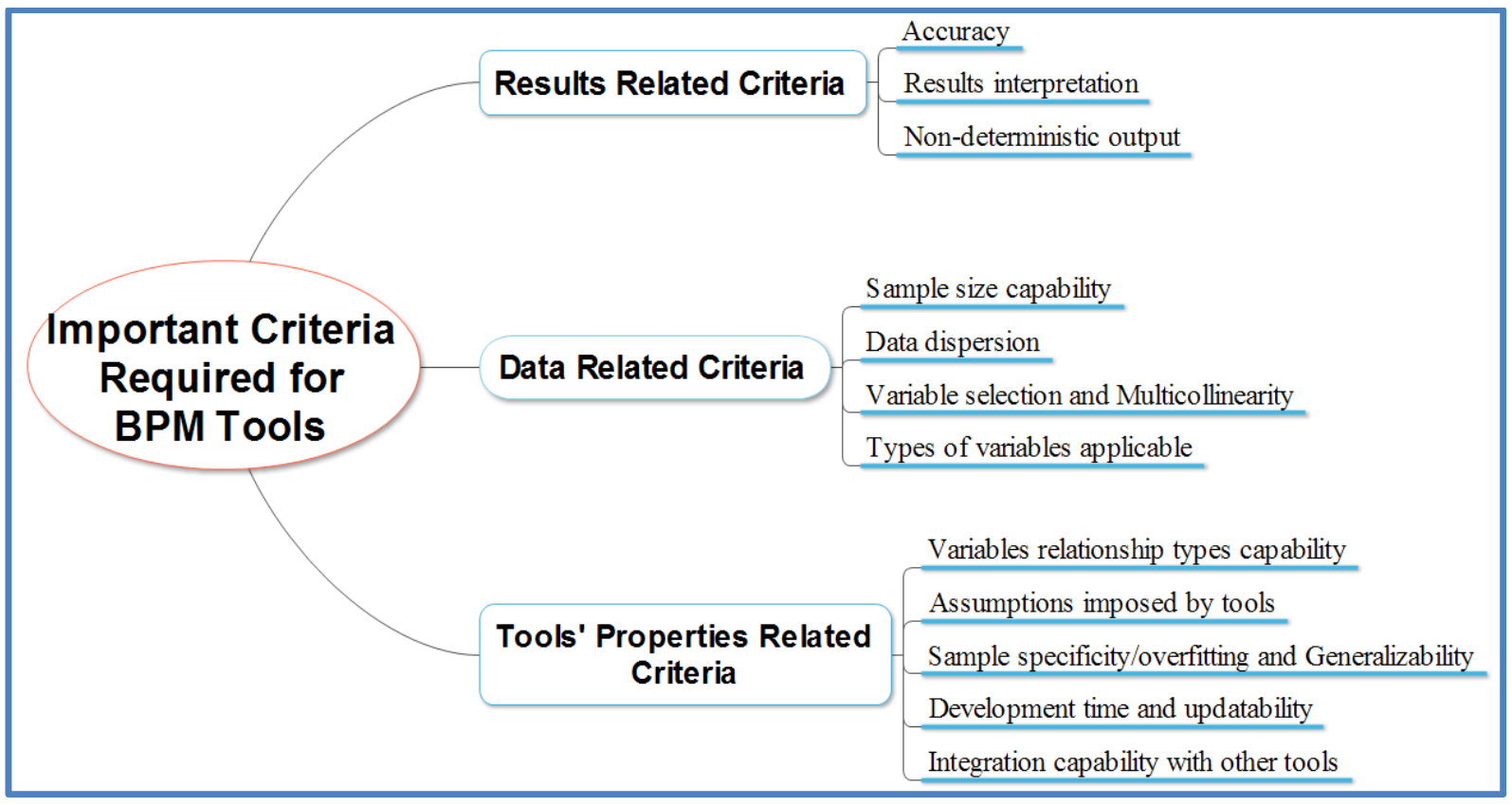

Figure 2: Important criteria required for BPM tools

\subsection{Results and Discussion}

This section presents the results, analysis and discussion of the systematic review in form of summary of findings tables and statistical charts. The results are presented in relation to each identified criterion. The tables and charts compare the performance/ability of the tools as deduced from all the reviewed studies. The outcome is used to judge each tool based on the criterion in question. The criteria were assessed and discussed in the context of bankruptcy prediction models (BPM). For example, to assess the accuracy criteria of the tools, error cost had to be considered since it is an important aspect of accuracy assessment in the BPM research area.

Not all the reviewed studies provided necessary tool information required to assess a tool under each criterion. Where a tool had too few studies providing information regarding a criterion, the tool was excluded from the 
statistical analysis regarding that criterion. The measure for exclusion was determined by calculating the average number of studies that provided information on the tools regarding the criterion in consideration; the tools with numbers well below average were excluded. This process, where employed, is clearly explained.

\subsection{Results Related Criteria}

\subsubsection{Accuracy}

One of the main essences of using varying tools to develop BPMs is to increase accuracy of prediction. Figure 3 shows the mean average accuracy chart for each tool calculated from all the studies that gave an accuracy reading for the tool. The chart includes only the tools that had up to 17 studies that reported an accuracy value for them since the mean average of number of studies that reported accuracy value is 17 (Table 1). The chart clearly shows ANN and SVM to be the most accurate while MDA appears to be the least accurate. Table 2 is the first summary of findings table. It shows the accuracy value of each tool as reported in each study.

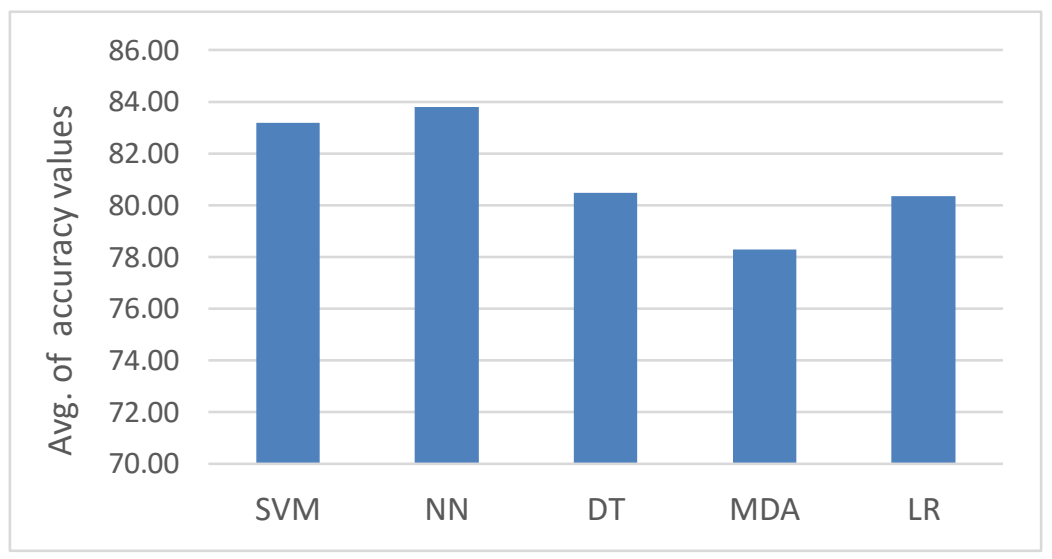

Figure 3: Overall average accuracy chart for each tool

Table 1: Summary statistics of the accuracy and error types of the tools

\begin{tabular}{|l|c|c|c|c|}
\hline Tool & $\begin{array}{l}\text { No. of authors } \\
\text { that used tool }\end{array}$ & $\begin{array}{l}\text { No. of authors that } \\
\text { reported an accuracy value }\end{array}$ & $\begin{array}{l}\text { No. of authors that } \\
\text { reported Type I error }\end{array}$ & $\begin{array}{l}\text { No. of authors that } \\
\text { reported Type II error }\end{array}$ \\
\hline SVM & 24 & 22 & 10 & 11 \\
\hline ANN & 38 & 37 & 18 & 18 \\
\hline DT & 19 & 17 & 5 & 1 \\
\hline RS & 4 & 4 & 1 & 4 \\
\hline GA & 10 & 6 & 0 & 0 \\
\hline CBR & 4 & 3 & 7 & 7 \\
\hline MDA & 21 & 19 & 12 & 12 \\
\hline LR & 31 & 28 & $\mathrm{fo}=57$ & $\mathrm{ft}=59$ \\
\hline Total & $\mathrm{Fu}=151$ & $\mathrm{fac}=136$ & $\sum \mathrm{fo} / \sum \mathrm{f}=7.1$ & $\sum \mathrm{ft} / \sum \mathrm{f}=7.35$ \\
\hline Mean & & $\sum \mathrm{fac} / \sum \mathrm{f}=17$ & & \\
\hline
\end{tabular}


Table 2: Summary of reviewed studies aims, variable selection methods, sample characteristics and accuracy values

\begin{tabular}{|c|c|c|c|c|c|c|c|c|c|c|c|c|c|c|c|}
\hline \multirow[t]{2}{*}{$\mathbf{S} / \mathbf{N}$} & \multirow[t]{2}{*}{ Author Year } & \multirow[t]{2}{*}{ Aim of study } & \multirow[t]{2}{*}{$\begin{array}{l}\text { Variable selection } \\
\text { method }\end{array}$} & \multirow{2}{*}{$\begin{array}{l}\text { Samp } \\
\text { le } \\
\text { size }\end{array}$} & \multirow{2}{*}{$\begin{array}{l}\% \text { of } \\
\text { Exist } \\
\text { firms }\end{array}$} & \multirow{2}{*}{$\begin{array}{l}\% \text { of } \\
\text { Fail } \\
\text { firms }\end{array}$} & \multirow{2}{*}{$\begin{array}{l}\% \\
\text { for } \\
\text { val. }\end{array}$} & \multicolumn{8}{|c|}{ Accuracy values } \\
\hline & & & & & & & & SVM & ANN & DT & RS & GA & CBR & MDA & LR \\
\hline 1. & $\begin{array}{l}\text { Tseng and } \mathrm{Hu} \\
(2010)\end{array}$ & Comparing models & $\begin{array}{l}\text { Literature rev. } \\
\text { (stepwise) }\end{array}$ & 77 & 58.4 & 41.6 & 20 & & 93.75 & & & & & & 86.25 \\
\hline 2. & Cho et al. (2010) & Propose new CBR approach & $\begin{array}{l}\text { t-test\& decision } \\
\text { tree }\end{array}$ & 1000 & 50 & 50 & 20 & & 71.8 & 65.7 & & & 73.7 & & 72.2 \\
\hline 3. & Kim \& Kang (2010) & $\begin{array}{l}\text { Check enhanced ANN against ord. } \\
\text { ANN }\end{array}$ & $\begin{array}{l}\text { cumulative } \\
\text { accuracy profiles }\end{array}$ & 1458 & 50 & 50 & 10 & & 71.02 & & & & & & \\
\hline 4. & $\begin{array}{l}\text { Yoon \& Kwon } \\
(2010)\end{array}$ & $\begin{array}{l}\text { Use credit card data for small bus. \& } \\
\text { compare techniques }\end{array}$ & t-test \& chi-square & 10000 & 50 & 50 & 30 & 74.2 & 73.1 & & & & & 70.1 & 70.1 \\
\hline 5. & Du Jardin (2010) & $\begin{array}{l}\text { To Check variable selection methods } \\
\text { effect }\end{array}$ & $\begin{array}{l}\text { Error backward- } \\
\text { order (stepwise) }\end{array}$ & 1020 & 50 & 50 & 49 & & 94.03 & & & & & 87.20 & 92.01 \\
\hline 6. & Lin et al. (2010) & $\begin{array}{l}\text { Use SVM with ratios \& non-fin. } \\
\text { variables }\end{array}$ & Stepwise regression & 108 & 50 & 50 & & 94.44 & & & & & & 90.74 & \\
\hline 7. & Gepp et al. (2010) & Compare DT \& MDA & Lit. rev (stepwise) & 200 & 71 & 29 & 20 & & & 87.6 & & & & 84.5 & \\
\hline 8. & $\begin{array}{l}\text { De Andrés et al. } \\
\text { (2011) }\end{array}$ & $\begin{array}{l}\text { Propose hybrid model (C-means \& } \\
\text { MARS) }\end{array}$ & $\begin{array}{l}\text { Altman's ratios } \\
\text { (stepwise) }\end{array}$ & $\begin{array}{l}5947 \\
4\end{array}$ & 99.77 & 0.23 & 20 & & 92.38 & & & & & 91.44 & 86.56 \\
\hline 9. & Kim (2011) & Compare techniques & Stepwise & 66 & 50 & 50 & & 95.95 & 91.6 & & & & & 72.6 & 80 \\
\hline 10. & Yang et al. (2011) & Propose hybrid model (PLS \& SVM) & Pearson cor. \& PLS & 120 & 53.3 & 46.7 & 100 & 79 & 78.33 & & & & & & \\
\hline 11. & Chen (2011) & Use PSO with SVM & $\begin{array}{l}\text { Lit. rev. (stepwise), } \\
\text { GA }\end{array}$ & 80 & 50 & 50 & 20 & & & & & & & & \\
\hline 12. & $\begin{array}{l}\text { Divsalar et al. } \\
\text { (2011) }\end{array}$ & Use GA \& NN & SFS & 150 & 51.4 & 48.6 & & & 82.5 & & & 95 & & & 80 \\
\hline 13. & $\begin{array}{l}\text { Du Jardin \& Séverin } \\
\text { (2011) }\end{array}$ & Use self-organizing map & $\begin{array}{l}\text { Error backward- } \\
\text { order (stepwise) }\end{array}$ & 2360 & 50 & 50 & 37.3 & & 82.61 & & & & & 81.93 & 81.14 \\
\hline 14. & Chen et al. (2011b) & Integrate error cost into model & & 1200 & 50 & 50 & 20 & 90 & 90.6 & & & 86.7 & & & \\
\hline 15. & Chen et al. (2011a) & Propose FKNN & & 240 & 53.3 & 46.7 & 10 & 76.67 & 79.58 & & & 83.33 & & & \\
\hline 16. & Li et al. (2011) & $\begin{array}{l}\text { Propose Random subspace LR } \\
\text { (RSBL) }\end{array}$ & Stepwise \& t-test & 370 & 50 & 50 & 30 & & & & 88.46 & & & 88.26 & 87.50 \\
\hline 17. & $\begin{array}{l}\text { Divsalar et al. } \\
\text { (2012) }\end{array}$ & Use new type of GA called GEP & SFS & 136 & 52.5 & 47.5 & 33.3 & & 79.41 & & & 91.18 & & & 76.47 \\
\hline 18. & Huang et al. (2012) & Propose hybrid KLFDA \& MR-SVM & & & & & 10 & 86.61 & 83.67 & 83.24 & & & & & 77.9 \\
\hline 19. & $\begin{array}{l}\text { Tsai \& Cheng } \\
\text { (2012) }\end{array}$ & Check effect of outlier on BPMs & & 653 & 45.3 & 54.7 & 10 & 86.37 & 86.06 & 84.69 & & & & & 86.37 \\
\hline 20. & Shie et al. (2012) & Proposed enhanced PSO-SVM & $\begin{array}{l}\text { Factor analysis \& } \\
\text { PCA }\end{array}$ & 54 & 55 & 44.4 & & 81.82 & 75.76 & 77.77 & & & & & 72.73 \\
\hline 21. & $\begin{array}{l}\text { Kristóf \& Virág } \\
(2012)\end{array}$ & & & 504 & 86.7 & 13.3 & 25 & & 88.7 & 88.8 & & & & & 88.5 \\
\hline 22. & Jeong et al. (2012). & To fine-tune ANN factors & GAM & 2542 & 50 & 50 & 20 & 79 & 81 & 76 & & & 73 & 73.5 & 76.48 \\
\hline 23. & $\begin{array}{l}\text { Du Jardin \& Séverin } \\
\text { (2012) }\end{array}$ & $\begin{array}{l}\text { To use Kohonen map to stabilize } \\
\text { temporal accuracy }\end{array}$ & & & & & & & 81.3 & & & & & 81.2 & 81.6 \\
\hline
\end{tabular}




\begin{tabular}{|c|c|c|c|c|c|c|c|c|c|c|c|c|c|c|c|}
\hline \multirow[t]{2}{*}{$\mathbf{S} /$} & \multirow[t]{2}{*}{ Author Year } & \multirow[t]{2}{*}{ Aim of study } & \multirow[t]{2}{*}{$\begin{array}{l}\text { Variable selection } \\
\text { method }\end{array}$} & \multirow{2}{*}{$\begin{array}{l}\text { Samp } \\
\text { le } \\
\text { size }\end{array}$} & \multirow{2}{*}{$\begin{array}{l}\% \text { of } \\
\text { Exist } \\
\text { firms }\end{array}$} & \multirow{2}{*}{$\begin{array}{l}\% \text { of } \\
\text { Fail } \\
\text { firms }\end{array}$} & \multirow{2}{*}{$\begin{array}{l}\% \\
\text { for } \\
\text { val. }\end{array}$} & \multicolumn{8}{|c|}{ Accuracy values } \\
\hline & & & & & & & & SVM & ANN & DT & $\mathbf{R S}$ & GA & CBR & MDA & LR \\
\hline 24. & $\begin{array}{l}\text { De Andrés et al. } \\
\text { (2012) }\end{array}$ & To improve performance of classifiers & & 122 & 50 & 50 & 19.6 & & 76.03 & & & & & 74.87 & \\
\hline 25. & Zhou et al. (2012) & $\begin{array}{l}\text { To find the best variables for } \\
\text { accuracy }\end{array}$ & $\begin{array}{l}\text { Spearman } \\
\text { correlation }\end{array}$ & & 50 & 50 & 10.8 & 71.1 & 67.8 & 75.6 & & & & 64.4 & 54.4 \\
\hline 26. & Xiong et al. (2013) & Use sequence on credit card data & & & & & & 70.94 & & & & & & & \\
\hline 27. & Lee \& Choi (2013) & To do multi industry investigation & $\begin{array}{l}\text { t-test \&correlation } \\
\text { analysis }\end{array}$ & 1775 & 66.2 & 33.8 & 4.2 & & 92 & & & & & 82.01 & \\
\hline 28. & Tsai \& Hsu (2013) & $\begin{array}{l}\text { Present met-learning framework } \\
\text { (hybrid) }\end{array}$ & $\mathrm{MC}$ & $\begin{array}{l}\text { Avg. } \\
\text { many }\end{array}$ & & & 20 & & 78.82 & 77.29 & & & & & 79.11 \\
\hline 29. & Callejón et al (2013) & To increase predictive power of ANN & & 1000 & 50 & 50 & 20 & & 92.11 & & & & & & \\
\hline 30. & Chuang (2013) & To Hybridise CBR & Multiple & 321 & 86.9 & 13.1 & & & & & & & 90.1 & & \\
\hline 31. & Ho et al. (2013) & $\begin{array}{l}\text { Develop BPM for US paper } \\
\text { companies }\end{array}$ & Lit rev (stepwise) & 366 & 66.7 & 33.3 & 20 & & & & & & & & 93 \\
\hline 32. & $\begin{array}{l}\text { Arieshanti et al. } \\
\text { (2013) }\end{array}$ & To compare techniques & Lit rev. (stepwise) & 240 & 53.3 & 46.7 & 20 & 70.42 & 71 & & & & & & \\
\hline 33. & Kasgari et al. (2013) & Compare ANN to other techniques & Garson's algorithm & 135 & 52.5 & 47.5 & 25 & & 94.11 & & & 88.57 & & & 91.43 \\
\hline 34. & Zhou et al. (2014) & Propose new feature selection method & GA & 2010 & 50 & 50 & & & 75.6 & 50.67 & & & & 71.72 & 73.99 \\
\hline 35. & Tsai (2014) & To compare hybrids & SOM & 690 & 44.5 & 55.5 & 20 & & 91.61 & 86.83 & & & & & 87.28 \\
\hline 36. & Yeh et al. (2014) & To increase accuracy using RF\&RS & RF & 220 & 75 & 25 & 33 & 94.58 & 92.95 & 91.55 & 96.99 & & & & \\
\hline 37. & Wang et al. (2014) & Inject feature selection into boosting & & 132 & 50 & 50 & 10 & 79.99 & 75.69 & 75.99 & & & & & 73.90 \\
\hline 38. & $\begin{array}{l}\text { Abellán \& Mantas } \\
\text { (2014) }\end{array}$ & To correctly use bagging scheme & Lit. rev. (stepwise) & 690 & & & 30 & & & & 93.64 & & & & \\
\hline 39. & Tserng et al. (2014) & $\begin{array}{l}\text { To use LR to predict contractors } \\
\text { default }\end{array}$ & & 87 & 66.7 & 33.3 & & & & & & & & & 79.18 \\
\hline 40. & Yu et al. (2014) & Produce BPM using ELM & & 500 & 50 & 50 & 33.3 & 93.2 & & & & & & 86.5 & \\
\hline 41. & Gordini (2014) & $\begin{array}{l}\text { Test GA accuracy \& compare to other } \\
\text { techniques }\end{array}$ & VIF \& stepwise & 3100 & 51.6 & 48.4 & 30 & 69.5 & & & & 71.5 & & & 66.8 \\
\hline 42. & Heo \& Yang (2014) & $\begin{array}{l}\text { To prove AdaBoost is right for } \\
\text { Korean construction firms }\end{array}$ & & 2762 & 50 & 50 & 20 & 73.3 & 77.1 & 73.1 & & & & 51.3 & \\
\hline 43. & Tsai et al. (2014) & To compare classifier ensembles & & 690 & 44.5 & 55.5 & 10 & 86.37 & 84.38 & 86.37 & & & & & \\
\hline 44. & $\begin{array}{l}\text { Virág \& Nyitrai } \\
\text { (2014) }\end{array}$ & $\begin{array}{l}\text { To show RS accuracy is competitive } \\
\text { with SVM \& ANN }\end{array}$ & & 156 & 50 & 50 & 25 & 89.32 & 88.03 & & 89.32 & & & & \\
\hline 45. & Liang et al. (2015) & To compare feature selections & GA & 688 & 50 & 50 & 10 & 91.77 & 91.63 & 92.98 & & & & & \\
\hline 46. & $\begin{array}{l}\text { Iturria1 \& Sanz } \\
\text { (2015) }\end{array}$ & To develop ANN BPM for US banks & $\begin{array}{l}\text { Mann-Whintney } \\
\text { test \& Gini index }\end{array}$ & 772 & 50 & 50 & 13.5 & 89.42 & 93.27 & & & & & 77.88 & 81.73 \\
\hline 47. & Du Jardin (2015) & $\begin{array}{l}\text { To improve BPM accuracy beyond } \\
\text { one year }\end{array}$ & & 16880 & 50 & 50 & 50 & & 80.8 & & & & & 80.1 & 80.6 \\
\hline 48. & Bemš et al. (2015). & $\begin{array}{l}\text { Introduce new scoring method called } \\
\text { Gini index }\end{array}$ & Gini index & 459 & 67 & 33 & 579 & & 0.291 & & & & 0.199 & 0.207 & 0.301 \\
\hline 49. & $\begin{array}{l}\text { Khademolqorani et } \\
\text { al. (2015) }\end{array}$ & To develop a novel hybrid & Factor analysis & 180 & & 58 & & & 94 & 94 & & & & 77 & 80 \\
\hline
\end{tabular}


Cor.: correlation

ELM: extreme learning machine

Exist firms: non bankrupt firms

Fail

firms: bankrupt firms $\quad$ FKNN: fuzzy $k$-nearest neighbour

GAM: generalized additive model

GEP:

gene expression programming

Lit. Literature K

MARS: Multivariate Adaptive Regression Splines

MC: meta classifier Rev.: review MR:

manifold-regularized PCA: principal component analysis

PLS: partial least squares

swarm optimization

RF: random forest RSBL: random subspace binary logit

PSO: particle

sequential feature selection

SOM: self-Organising maps

Val.: Validation VIF: variance Inflation Factor

Note: Bems et al. (2015) scoring methods results are not used as they will act as outliers in the computations of mean average and disadvantage accuracy results of tools that have them. Chen (2011) results were not clear enough to be included for computational analysis

The chart in Figure 4 shows a more direct comparison between pair of tools. It shows the average accuracy value calculated from studies that directly compared any pair of tools. The chart includes only the pairs that were compared in five or more studies since the mean average of the number of times any two tools were directly compared is 5.5 (see Table 3). To be more objective and fair in analysis, and to make a good critique, the pie charts in Figure 5 is produced to compare the percentage of studies that rated one tool as being more accurate than the other. It contains exactly the same pairs as Figure 4.

Figures 3, 4 and 5 all show that AI tools are more accurate than statistical tools except in Figure 5j where the number of studies that indicated that DT is more accurate than LR and vice versa are equal. Figures 4 and 5a-d clearly show SVM to be more accurate than any directly comparing tool though Figure 3, which is just the average accuracy of each tool, shows ANN to be more accurate. SVM apart, Figures 4 and 5e-h similarly show ANN to be more accurate than any comparing tool except for GA; with three against two studies confirming GA to be more accurate.

Table 3: Matrix of number of times studies directly compared pair of tools. The tools compared above the average number of comparisons are in bold

\begin{tabular}{|l|c|c|c|c|c|c|c|c|c|}
\hline & SVM & ANN & DT & RS & GA & CBR & MDA & LR & Total \\
\hline SVM & - & $\mathbf{1 8}$ & 10 & 2 & 3 & 1 & 8 & 10 & \\
\hline ANN & $\mathbf{1 8}$ & - & 16 & 2 & 5 & 3 & 16 & 25 & \\
\hline DT & $\mathbf{1 0}$ & $\mathbf{1 6}$ & - & 1 & 0 & 2 & 6 & 12 & \\
\hline RS & 2 & 2 & 1 & - & 0 & 0 & 1 & 1 & \\
\hline GA & 3 & 5 & 0 & 0 & - & 0 & 0 & 4 & \\
\hline CBR & 1 & 3 & 2 & 0 & 0 & - & 2 & 3 & \\
\hline MDA & $\mathbf{8}$ & $\mathbf{1 6}$ & $\mathbf{6}$ & 1 & 0 & 2 & -- & 14 & \\
\hline LR & $\mathbf{1 0}$ & $\mathbf{2 5}$ & $\mathbf{1 2}$ & 1 & $\mathbf{4}$ & 3 & $\mathbf{1 4}$ & - & \\
\hline Total & 53 & 67 & 21 & 2 & 4 & 5 & 14 & 0 & 165 \\
\hline Mean Average & & & & & $165 / 30=5.5$ & & & \\
\hline
\end{tabular}




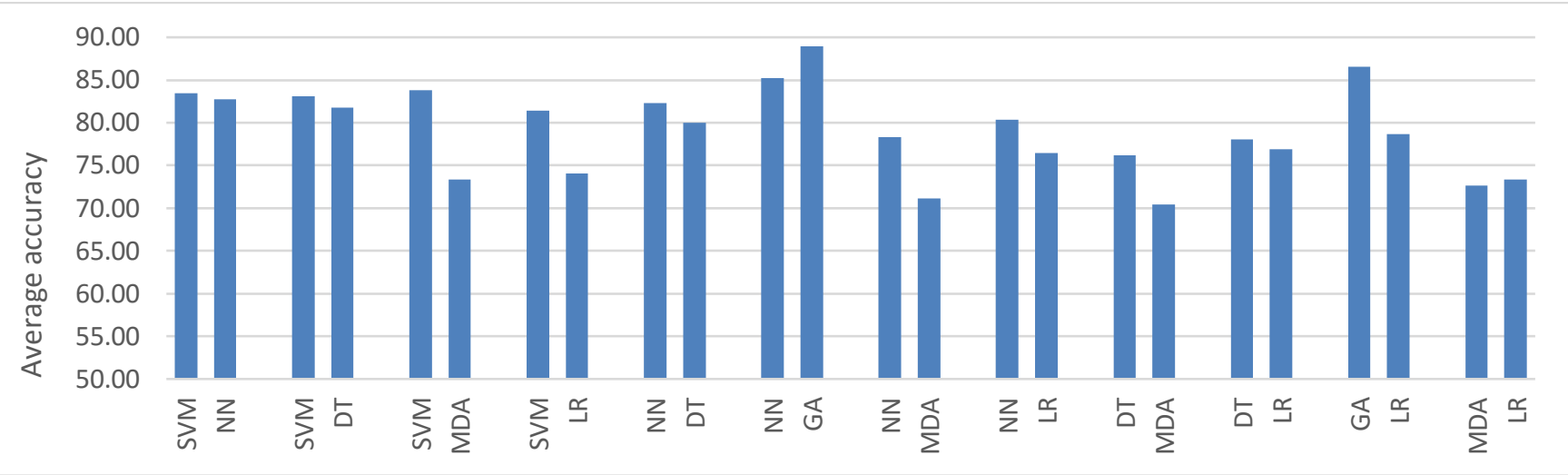

Figure 4: Average accuracy results only from studies that directly compared pair of tools
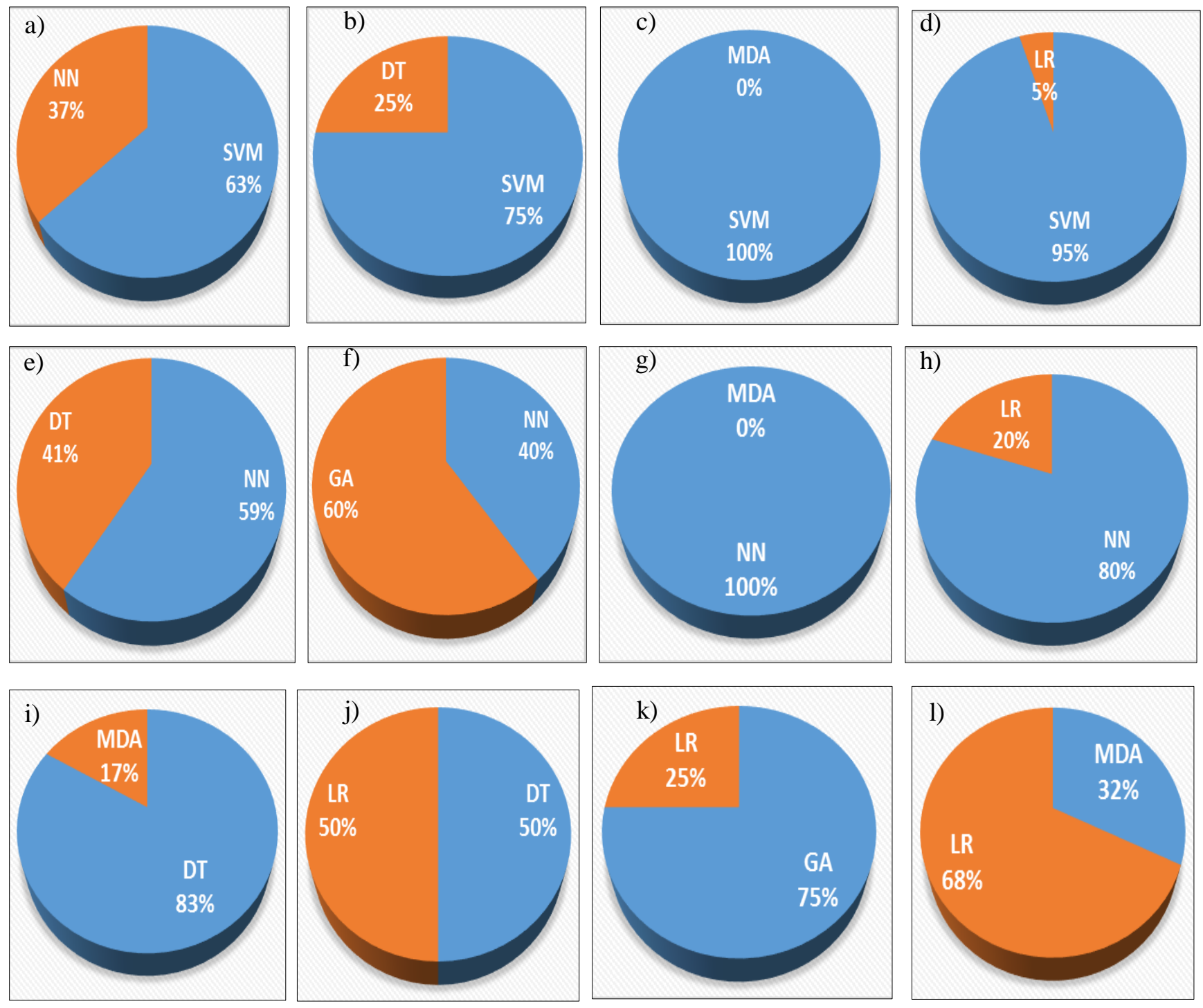

Figure 5: Pie charts that compare the percentage of studies that indicated one tool as being more accurate than the other. 
A further examination of the five studies that compared the pair (ANN and GA) revealed they were written by two main set of authors. Of the five studies, only Chen et al. (2011a), which reported ANN and SVM as being more accurate than GA (see Table 2) could be said to have done a fair comparison since it produced the results for ANN and GA using the same features. Chen et al. (2011b) in their study developed a robust hybrid of GA and K-nearest neighbour (KNN) and compared it with other tools including ANN and SVM in their standalone form thus giving GA the advantage. Divsalar et al. (2011) ‘unfairly' used a special version of GA called linear genetic programming (LGP) for comparison with normal ANN. Also, Divsalar et al. (2012) proposed a special version of GA called gene expression programming (GEP), thoroughly developed its BPM using all possible enhancements, and proved it was more accurate than models from other tools, including ANN developed with default settings.

Similarly, Kasgari et al. (2013), which included Divsalar as the second author, used the same data as Divsalar et al. (2012), proposed ANN for developing BPMs, thoroughly developed its model and proved it was more accurate than other tools, including GA. Besides, GA is well known to be more suited to the process of feature/variable selection because of its powerful global search hence its relatively infrequent use to develop BPMs (see Figure 6); it was used for this purpose in at least four of the primary studies (Chen, 2011; Jeong et al., 2012; Zhou et al., 2014; Liang et al. 2015) and other studies. Further "GA is a stochastic one. So, when using GA-based models on the same training samples twice, we may get two different models, and the decision on the same test sample may also be different. This stochastic characteristic of this method may be unacceptable for the decision makers or the analysts" (Zhou et al. 2014, p,252). SVM and ANN can thus be claimed to be more accurate. As noted in some of the reviewed studies (e.g. Virág and Nyitrai, 2014; Iturriaga and Sanz, 2015), this is in line with literature as it is mostly agreed that SVM and ANN are the most accurate tools for developing BPMs.

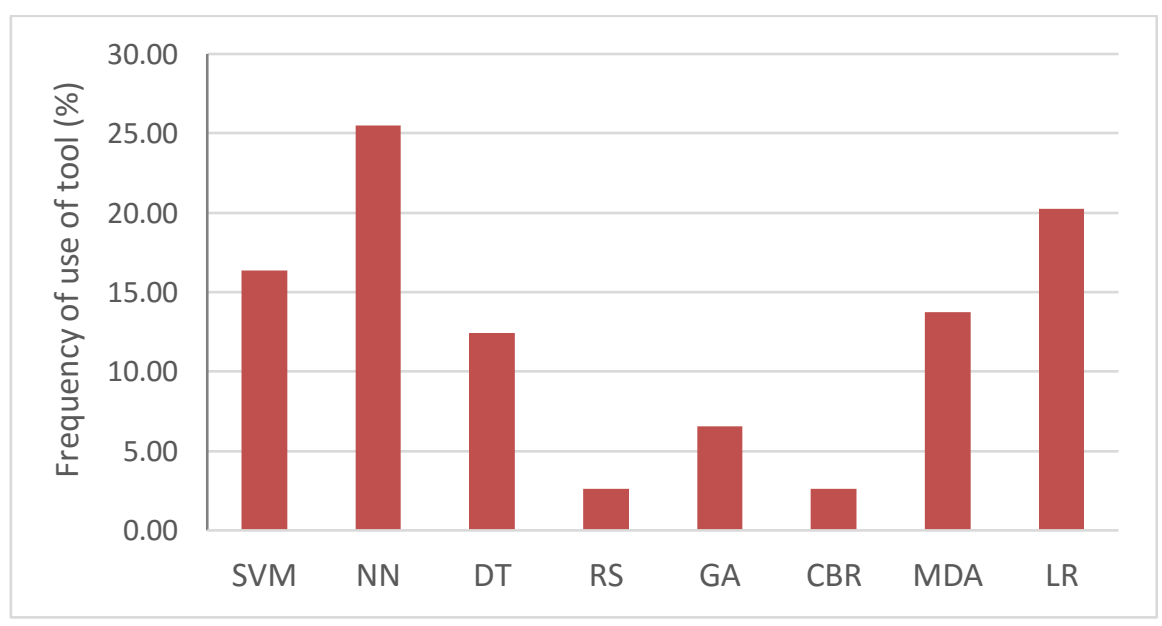

Figure 6: Percentage frequency of use of each tool

No study compared RS directly with GA. However, RS and ANN as well as SVM were compared directly in two studies and RS gave a slightly better result. Like the unfair cases with GA, Yeh et al. (2014) thoroughly developed 
many RS hybrid models using various enhancements and compared their average accuracy value to single accuracy values of separate hybrids of ANN and SVM. In the second study, Virág and Nyitrai (2014), working further from their previous study which confirmed SVM and ANN to be most accurate tools, decided to check why nontransparent tools (i.e. SVM and ANN) were more accurate than transparent tools like RS. They (Virág and Nyitrai 2014) initially concluded "there seems to be a kind of trade-off between the interpretability and predictive power of bankruptcy models" (p.420) so they tried to find out what to use with "RST technique in order to maximise the predictive power of the constructed model?" In other words, special effort was made to improve RS accuracy while SVM and ANN were used at default level; this obviously resulted in a biased result. Despite the effort, RS was only able to achieve the same accuracy as SVM and only a slightly higher accuracy than ANN (Table 3). Besides, Ravi Kumar and Ravi (2007) showed in their review that RS is not as accurate as claimed in many studies and Mckee (2003) reported a significantly reduced accuracy, compared to his previous study, when used with what was termed a 'more realistic' data. RS theory is difficult to implement hence its sparse usage (see Figure 6).

While DT's average accuracy appears slightly higher than LR's in Figure 4, Figure $5 \mathrm{j}$ shows that the number of studies that indicated DT to be more accurate than LR and vice versa are the same. DT has generally been confirmed to be less accurate than other AI tools like ANN and RS (Tam and Kiang, 1992; Chung and Tam 1992; McKee, 2000; Ravi Kumar and Ravi, 2007) except CBR; it (DT) has been classified as a somewhat weak classifier in one of the reviewed studies (Heo and Yang 2014). CBR is the overall least accurate tool. Of the four studies that used it, Chuang (2013) used it alone without comparison to any other tools. Jeong et al. (2012) and Bemš et al. (2015) showed that it was the least accurate when compared to SVM, DT, ANN, MDA and LR (Table 2). Only Cho et al. (2010), who presented an enhanced and hybridised CBR using DT and Mahalanobis distance, which was the aim of the study, was able to get a better accuracy figure for CBR (hybrid) than ANN, MDA and LR (Table 2). CBR's low accuracy is a consequence of it not being able to handle non-linear problems and has been deemed by some as not suitable for bankruptcy prediction (e.g. Bryant, 1997; Ravi Kumar and Ravi, 2007). In the reviewed studies, Chuang (2013) noted that "one major factor for the poorer performance of a stand-alone CBR model lies in its failure to separate the more important "key" attributes from those less significant common attributes and to assign each key attribute with a different, corresponding weight" (p.184). No wonder it is very scarcely used for BPMs (see Figure 6). Of the two statistical models, LR is clearly the more accurate tool.

\subsubsection{Error Cost}

For accuracy ratings, error cost is a very important concept in bankruptcy prediction hence the tools must be appraised with regards to it. There are two types of error in bankruptcy prediction: type I and type II. Type I error is when a tool misclassifies a potentially bankrupt firm as being healthy. This is costlier as it could cause a financier to loan money to a failing firm and eventually lose the money, or it could make a firm relax when it is supposed to take active steps against insolvency. Type II error is when a tool misclassifies non-bankrupt firm as potentially 
bankrupt/failing. This error is less costly. This means a tool with relatively lesser type I error is more accurate. This, however, does not imply that type II error is unimportant as it could cost the firm its eligibility for loans, for example.

Since the mean average of frequency of reported types I and II errors are 7.36 and 7.63 respectively (Table 1), only the six tools that had up to 4 reporting studies and above were compared in the average types I and II error of tools chart in Figure 7. Four is deemed not too far from seven in this case so as to allow more tools to be compared. All error values are presented in Table 4. No study reported an error value for CBR while only one study reported for RS. Figure 7 shows that ANN has the least average type I error followed by SVM. Coupled with their high normal accuracy performance, they can be concluded to be the most accurate tools for bankruptcy prediction, followed by GA. DT and LR errors are again as close as their accuracies hence their total accuracy can be regarded to be of the same rank. However, MDA appears to be very poor with type I error hence its accuracy can be regarded as low. ANN, DT, GA and LR have better type I errors than type II errors and vice versa for SVM and MDA

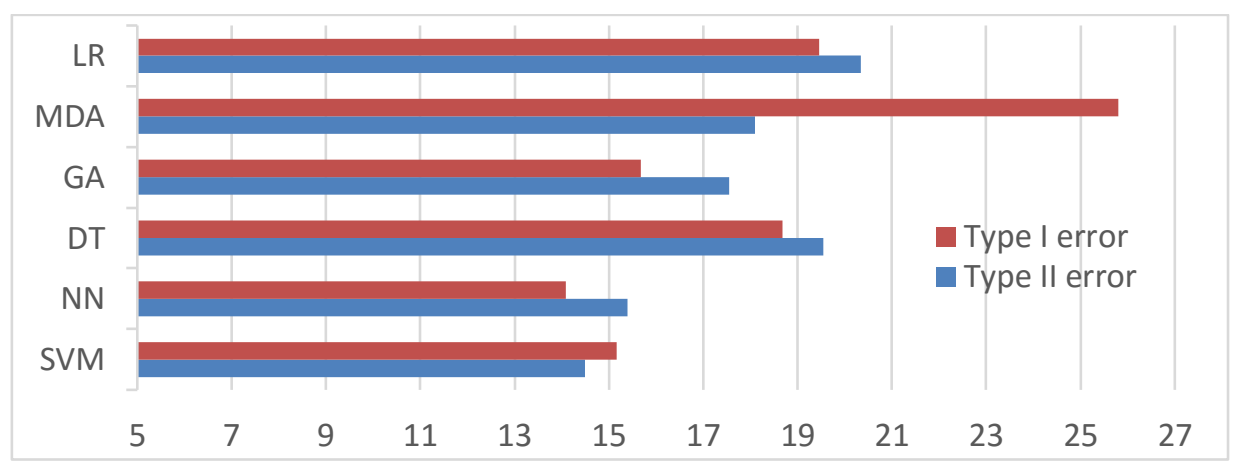

Figure 7: Type I versus Type II error for each tool

\subsubsection{Results Interpretation}

For financiers and potential clients, it is enough for a firm to be predicted as healthy or about to bankrupt. However, for firm owners to appreciate a prediction model, the model must give an indication of where a firm is going wrong if the firm is classified as a failing firm so that necessary steps can be taken to avoid total failure if possible. In this context, about a quarter of the studies that used SVM and ANN highlighted the 'black box' nature of the tools as a major problem (Table 5 and Figure 8). Other studies have also pointed out that the results of ANN and SVM models are quite hard to understand in that weightings/coefficients they assign to the variables are illogical and very hard to interpret (Tam and Kiang, 1992; Shin et al., 2005; Chung et al., 2008; Ahn and Kim, 2009; Tseng and $\mathrm{Hu}, 2010)$. 
Table 4: Summary of error types as reported for the tools by some of the authors

\begin{tabular}{|c|c|c|c|c|c|c|c|c|c|c|c|c|c|c|c|}
\hline \multirow[t]{2}{*}{$\mathbf{S} / \mathbf{N}$} & \multirow[t]{2}{*}{ Author Year } & \multicolumn{2}{|c|}{ SVM } & \multicolumn{2}{|c|}{ ANN } & \multicolumn{2}{|c|}{ DT } & \multicolumn{2}{|c|}{$\mathbf{R S}$} & \multicolumn{2}{|c|}{ GA } & \multicolumn{2}{|c|}{ MDA } & \multicolumn{2}{|c|}{ LR } \\
\hline & & $\begin{array}{l}\text { Type I } \\
\text { error }\end{array}$ & $\begin{array}{l}\text { Type } \\
\text { II } \\
\text { error }\end{array}$ & $\begin{array}{l}\text { Type I } \\
\text { error }\end{array}$ & $\begin{array}{l}\text { Type } \\
\text { II } \\
\text { error }\end{array}$ & $\begin{array}{l}\text { Type I } \\
\text { error }\end{array}$ & $\begin{array}{l}\text { Type } \\
\text { II } \\
\text { error }\end{array}$ & $\begin{array}{l}\text { Type I } \\
\text { error }\end{array}$ & $\begin{array}{l}\text { Type } \\
\text { II } \\
\text { error }\end{array}$ & $\begin{array}{l}\text { Type I } \\
\text { error }\end{array}$ & $\begin{array}{l}\text { Type } \\
\text { II } \\
\text { error }\end{array}$ & $\begin{array}{l}\text { Type I } \\
\text { error }\end{array}$ & $\begin{array}{l}\text { Type } \\
\text { II } \\
\text { error }\end{array}$ & $\begin{array}{l}\text { Type I } \\
\text { error }\end{array}$ & $\begin{array}{l}\text { Type } \\
\text { II } \\
\text { error }\end{array}$ \\
\hline 1. & Kim \& Kang (2010) & & & 17.23 & 30.83 & & & & & & & & & & \\
\hline 2. & Yoon \& Kwon (2010) & 11.34 & 25.14 & & & & & & & & & & & & \\
\hline 3. & Du Jardin (2010) & & & 4.72 & 7.22 & & & & & & & 16.8 & 8.8 & 9.58 & 6.4 \\
\hline 4. & Lin et al. (2010) & 5.56 & 5.56 & & & & & & & & & & & & \\
\hline 5. & $\operatorname{Kim}(2011)$ & & & 4.8 & 12.1 & & & & & & & 47.6 & 27.4 & 22 & 18.4 \\
\hline 6. & Yang et al. (2011) & 8.93 & 17.2 & 16.07 & 26.56 & & & & & & & & & & \\
\hline 7. & Du Jardin \& Séverin (2011) & & & 17.95 & 16.82 & & & & & & & 18.41 & 17.73 & 18.18 & 19.55 \\
\hline 8. & Chen et al. (2011b) & 15.7 & 4.3 & 12.2 & 6.7 & & & & & 17.1 & 9.7 & & & & \\
\hline 9. & Chen et al. (2011a) & 26.55 & 18.96 & 18.52 & 21.71 & & & & & 14.94 & 17.02 & & & & \\
\hline 10. & Divsalar et al. (2012) & & & 15.79 & & & & & & 9.52 & 7.69 & & & 20 & \\
\hline 11. & Tsai \& Cheng (2012) & 19.9 & 6.1 & 12.1 & 16.2 & 13.5 & 17.6 & & & & & & & 17.4 & 9.1 \\
\hline 12. & Shie et al. (2012) & & 16.7 & & 17.65 & & 22.23 & & & & & & & & 25 \\
\hline 13. & Du Jardin \& Séverin (2012) & & & 20.1 & 17.4 & & & & & & & 22.1 & 15.5 & 20.1 & 16.6 \\
\hline 14. & De Andrés et al. (2012) & & & 26.52 & 21.71 & & & & & & & 28.7 & 22.08 & 25.67 & 21.35 \\
\hline 15. & Lee \& Choi (2013) & & & 12.0 & 6.0 & & & & & & & 24 & 14 & & \\
\hline 16. & Tsai \& Hsu (2013) & & & 20.19 & 28.63 & 21.57 & 33.02 & & & & & & & 17.87 & 30.67 \\
\hline 17. & Kasgari et al. (2013) & & & 5.0 & 7.14 & & & & & & & & & & \\
\hline 18. & Tsai (2014) & & & 6.87 & 10.09 & 9.21 & 17.82 & & & & & & & 13.79 & 11.36 \\
\hline 19. & Yeh et al. (2014) & 11.02 & 3.74 & 18.02 & 4.32 & 26.0 & 1.90 & 10.6 & 3.5 & & & & & & \\
\hline 20. & Wang et al. (2014) & 21.55 & 18.19 & 20.62 & 27.69 & 23.10 & 24.74 & & & & & & & 26.38 & 25.38 \\
\hline 21. & Gordini (2014) & 22.9 & 38.1 & & & & & & & 21.1 & 35.8 & & & 23.3 & 43.1 \\
\hline 22. & Iturria1 \& Sanz (2015) & 11.54 & 9.62 & 5.77 & 7.69 & & & & & & & 23.08 & 21.15 & 19.23 & 17.31 \\
\hline
\end{tabular}

As noted by at least five of the reviewed studies (Table 5) and older studies (e.g. Ohlson, 1980; Tam and Kiang, 1992; Boritz and Kennedy, 1995;

Balcaen and Ooghe, 2006 among others), the variable coefficients in LR represent the importance of variables thus its result is transparent and help users identify key areas of problem of a failing firm. As noted by at least five of the reviewed studies (Table 5) and some previous studies (Tam and Kiang, 1992; McKee, 2000; Greco et al., 2001; Shin and Lee, 2002; Shin et al., 2005; Ravi Kumar and Ravi, 2007), AI tools that generate decision rules for classification (i.e. RS, CBR, GA and DT) all produce explanatory results that can be easily interpreted and understood. It appears that for AI tools, the more accurate the tool, the less transparent the result (Figure 9). Nonetheless, McKee (2000) once spotted an inconsistency in a set of rules generated by RS in one of his previous co-authored studies. 
Table 5: Summary of tools that have been highlighted to be transparent, usable as hybrid, updatable, have overfitting problems etc., and year, country industry of the samples used in the reviewed studies

\begin{tabular}{|c|c|c|c|c|c|c|c|c|c|c|}
\hline $\begin{array}{l}\mathbf{S} \\
\text { l } \\
\mathbf{N} \\
\end{array}$ & Author & Journal of Publication & $\begin{array}{l}\text { Req. small } \\
\text { sample } \\
\text { size }\end{array}$ & Hybrid & $\begin{array}{l}\text { Upda } \\
\text { teabl } \\
\text { e }\end{array}$ & Black box & $\begin{array}{l}\text { Transp } \\
\text { arent }\end{array}$ & $\begin{array}{l}\text { Multicolli } \\
\text { nearity } \\
\text { check }\end{array}$ & $\begin{array}{l}\text { Overfit } \\
\text { reported }\end{array}$ & Country \\
\hline 1. & Tseng and $\mathrm{Hu}(2010)$ & Expert Systems with Applications & & & & & & & $\mathrm{NN}$ & England \\
\hline 2. & Cho et al. (2010) & Expert Systems with Applications & & & & & DT & & & Korea \\
\hline 3. & Kim \& Kang (2010) & Expert Systems with Applications & & NN & & & & NN & NN & Korea \\
\hline 4. & Yoon \& Kwon (2010) & Expert Systems with Applications & & & & & & & NN, SVM & \\
\hline 5. & Du Jardin (2010) & .Neurocomputing & & & & & & & & France \\
\hline 6. & Lin et al. (2010) & $\begin{array}{l}\text { Journal of Marine Science and } \\
\text { Technology }\end{array}$ & & & & & & & & Taiwan \\
\hline 7. & Gepp et al. (2010) & Journal of forecasting & & & & & DT & & & US \\
\hline 8. & De Andrés et al. (2011) & Knowledge-Based Systems & & NN & & & & & & Spain \\
\hline 9. & Kim (2011) & Expert Systems with Applications & & & & MDA & LR & MDA, LR & NN & Korea \\
\hline 10. & Yang et al. (2011) & Expert Systems with Applications & SVM & SVM & & SVM, NN & & SVM, NN & & \\
\hline 11. & Chen (2011) & Neural Network World & SVM & SVM, GA & & & & SVM, GA & & Taiwan \\
\hline 12. & Divsalar et al. (2011) & Expert Systems & & & GA & $\mathrm{NN}$ & GA & GA & & Iran \\
\hline 13. & Du Jardin \& Séverin (2011) & Decision Support Systems & & & & & & MDA, LR & & France \\
\hline 14. & Chen et al. (2011b) & Knowledge-Based Systems & & & & & & & GA & France \\
\hline 15. & Chen et al. (2011a) & Expert Systems with Applications & & GA & & & & & & \\
\hline 16. & Li et al. (2011) & Knowledge-Based Systems & & & & & & & & China \\
\hline 17. & Divsalar et al. (2012) & Journal of Forecasting & & & & NN & $\begin{array}{l}\text { GA, } \\
\text { LR }\end{array}$ & & GA & Iran \\
\hline 18. & Huang et al. (2012) & Expert Systems with Applications & SVM & $\begin{array}{l}\text { SVM, } \\
\text { MDA }\end{array}$ & & & & & SVM, NN, DT & \\
\hline 19. & Tsai \& Cheng (2012) & Knowledge-Based Systems & & & & & & & & Japan \\
\hline 20. & Shie et al. (2012) & Neural Computing and Applications & & SVM, GA & & & LR & DT & & USA \\
\hline 21. & Kristóf \& Virág (2012) & Acta Oeconomica & & & & NN & DT, LR & LR & DT, LR & \\
\hline 22. & Jeong et al. (2012). & Expert Systems with Applications & & $\begin{array}{l}\text { SVM, NN, } \\
\text { GA }\end{array}$ & & SVM, NN & & & NN & Korea \\
\hline 23. & Du Jardin \& Séverin (2012) & $\begin{array}{l}\text { European Journal of Operational } \\
\text { Research }\end{array}$ & & & & & & MDA & NN & France \\
\hline 24. & De Andrés et al. (2012) & Knowledge-Based Systems & & & & NN & & MDA & & Spain \\
\hline 25. & Zhou et al. (2012) & $\begin{array}{l}\text { Computers \& Mathematics with } \\
\text { Applications }\end{array}$ & & & & & & & & USA \\
\hline 26. & Xiong et al. (2013) & Expert Systems with Applications & & SVM & & & & & & \\
\hline 27. & Lee \& Choi (2013) & Expert Systems with Applications & & & & & & & NN & Korea \\
\hline 28. & Tsai \& Hsu (2013) & Journal of Forecasting & & $\begin{array}{l}\text { NN, DT, } \\
\text { LR }\end{array}$ & & & & & & \\
\hline
\end{tabular}




\begin{tabular}{|c|c|c|c|c|c|c|c|c|c|c|}
\hline $\begin{array}{l}\mathbf{S} \\
\text { l } \\
\mathbf{N}\end{array}$ & Author & Journal of Publication & $\begin{array}{l}\text { Req. small } \\
\text { sample } \\
\text { size }\end{array}$ & Hybrid & $\begin{array}{l}\text { Upda } \\
\text { teabl } \\
\text { e }\end{array}$ & Black box & $\begin{array}{l}\text { Transp } \\
\text { arent }\end{array}$ & $\begin{array}{l}\text { Multicolli } \\
\text { nearity } \\
\text { check }\end{array}$ & $\begin{array}{l}\text { Overfit } \\
\text { reported }\end{array}$ & Country \\
\hline 29. & Callejón et al. (2013) & $\begin{array}{l}\text { International Journal of } \\
\text { Computational Intelligence Systems }\end{array}$ & & & & & & & & multiple \\
\hline 30. & Chuang (2013) & Information Sciences & & $\begin{array}{l}\text { CBR, RS, } \\
\text { DT }\end{array}$ & CBR & & & & & \\
\hline 31. & Ho et al. (2013) & Empirical Economics & & & & & & & & US \\
\hline 32. & Arieshanti et al. (2013) & $\begin{array}{l}\text { TELKOMNIKA (Telecommunication } \\
\text { Computing Electronics and Control) }\end{array}$ & & $\begin{array}{l}\text { SVM, NN, } \\
\text { LR }\end{array}$ & & & & & & \\
\hline 33. & Kasgari t al. (2013). & Neural Computing and Applications & & & & NN & & & NN & Iran \\
\hline 34. & Zhou et al. (2014) & $\begin{array}{l}\text { International Journal of Systems } \\
\text { Science }\end{array}$ & SVM & $\begin{array}{l}\text { SVM, NN, } \\
\text { DT, GA }\end{array}$ & & SVM, NN & & & SVM, NN, DT & US \\
\hline 35. & Tsai (2014) & Information Fusion & & $\begin{array}{l}\text { NN, DT, } \\
\text { LR }\end{array}$ & & & & & $\mathrm{NN}$ & Australia \\
\hline 36. & Yeh et al. (2014) & Information Sciences & & $\begin{array}{l}\text { SVM, NN, } \\
\text { DT, RS }\end{array}$ & & & & & & \\
\hline 39. & Tserng et al. (2014) & $\begin{array}{l}\text { Journal of Civil Engineering and } \\
\text { Management }\end{array}$ & & & & & & & LR & US \\
\hline 40. & Yu et al. (2014) & Neurocomputing & & SVM & & & & & & France \\
\hline 41. & Gordini (2014) & Expert Systems with Applications & & & & & LR & & SVM, GA & Italy \\
\hline 42. & Heo \& Yang (2014) & Applied Soft Computing & & & & & & & & Korea \\
\hline 43. & Tsai et al. (2014) & Applied Soft Computing & & & & & & & & Japan \\
\hline 44. & Virág \& Nyitrai (2014) & Acta Oeconomica & & & & & & & SVM, NN, RS & \\
\hline 45. & Liang et al. (2015) & Knowledge-Based Systems & & $\begin{array}{l}\text { SVM, NN, } \\
\text { DT, GA }\end{array}$ & & & & & & China \\
\hline 46. & Iturriaga \& Sanz (2015) & Expert Systems with Applications & & & & SVM, NN & & & SVM, NN & US \\
\hline 47. & Du Jardin (2015) & $\begin{array}{l}\text { European Journal of Operational } \\
\text { Research }\end{array}$ & & & & & & & & France \\
\hline 48. & Bemš et al. (2015). & Expert Systems with Applications & & & & & & & & \\
\hline 49. & $\begin{array}{l}\text { Khademolqorani et al. } \\
\text { (2015) }\end{array}$ & $\begin{array}{l}\text { Mathematical Problems } \\
\text { Engineering }\end{array}$ & & & & NN & & & NN, DT & Iran \\
\hline
\end{tabular}




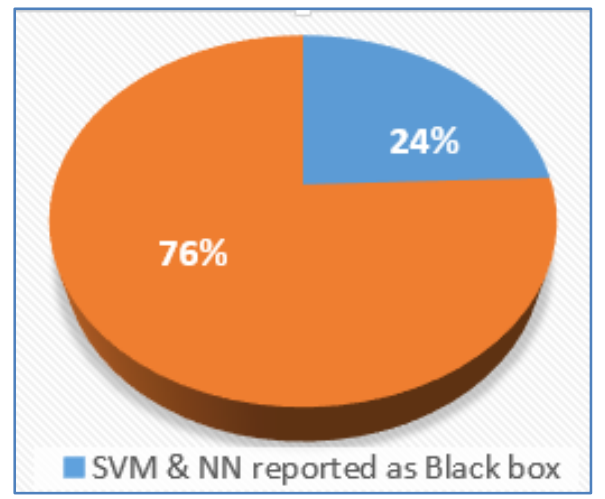

Figure 8: Percentage of studies that complained/noted the non-transparent nature of SVM and ANN

Kim (2011) and older studies (Altman, 1968; Taffler, 1983; Tam and Kiang, 1992; Balcaen and Ooghe, 2006) noted that although the MDA function makes MDA result look easily interpretable, the truth is that the variables' coefficients in the function do not represent their importance, hence results are hard to interpret. Further, MDA sometimes yields a model with counter intuitive signs (Edum-Fotwe et al., 1996; Balcaen and Ooghe, 2006). One of many example models is Mason and Harris' (1979) in which a negative sign was assigned to the profit before tax variable while representing firms with scores above cut-off as being healthy. This means profit is bad for a firm's health! This is obviously incomprehensible.

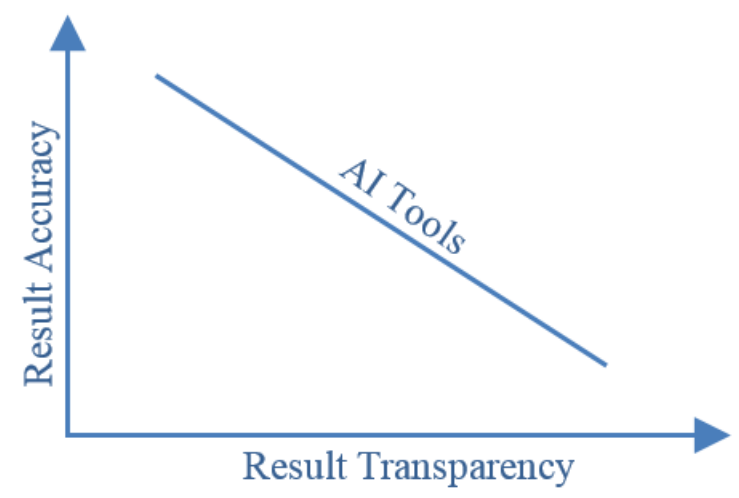

Figure 9: Relationship between the accuracy and transparency of results of AI tools.

One relatively popular approach to transparency problem has been to use decision rules-generating tools to select variables and decide the importance of variables before using the very accurate black box tool for prediction. This, from the way it is explained, is obviously not the perfect answer as it sounds like using two separate tools for two different criteria. Kasgari et al. (2013, p.930) suggested that "to overcome this difficulty, the weights and biases are frozen after the network was well trained and then the trained MLP models are translated into explicit forms", but did not explain how this is done. 


\section{$\underline{\text { 5.1.3 Non-Deterministic Output }}$}

Unlike statistical tools and non-decision rules AI tools (i.e. ANN and SVM), AI tools that induce decision rules for classification can produce some non-deterministic rules i.e. rules that cannot be applied to a new object (firm) being assessed. The presence of non-deterministic rules for a new object can result into no classification (Ahn et al., 2000; McKee, 2000; Shin and Lee, 2002; Ravi Kumar and Ravi, 2007). Of the reviewed studies, Gordini (2014) highlighted GA as a tool that is synonymous with this problem. According to Shin and Lee (2002), as much as $46 \%$ of new cases might not be classified by these tools (GA was used in their study).

The non-deterministic problem is encountered in this group of tools because the set of rules extracted work like a multiple univariate system rather than a multivariate system. As a result, when any new case being assessed cannot satisfy any or all of the rules for one reason or the other, the non-deterministic problem arises. To curtail this problem, some studies have "reported that reduced data set (horizontally or vertically) is fed into neural network for complementing the limitation of RS, which finally produces full prediction of new case data" (Ahn et al., 2000, p. 68). Shin and Lee (2002) suggested the integration of multiple rules to solve the problem. For instance, if two of eight rules (two deterministic and six non-deterministic) show a new object as unhealthy, then the object is classified as unhealthy. Conclusively, it appears that there is no tool that clearly outperforms all other tools in relation to all result related criteria (Figure 10).

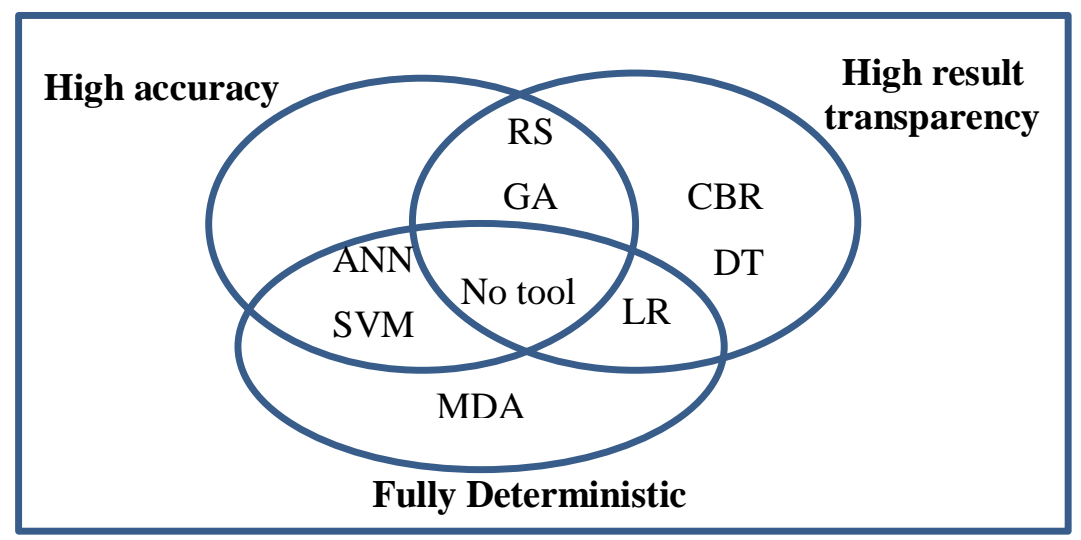

Figure 10: Performance of tools in relation to results related criteria. There is no one tool that satisfies all the results related criteria required to develop a robust prediction model.

\subsection{Data Related Criteria}

\subsubsection{Data Dispersion and Sample Size Capability}

Data dispersion, i.e. ratio of number of non-failing sample firms to failing sample firms, is known to be key to performance; the relative ease with which data on existing firms can be gathered usually makes them dominate data and reduce performance. According to Du Jardin (2015), this normally means that "data that characterized 
failed firms would be hidden by those that represent non-failed firms, and therefore would become rather useless" (p.291) hence it is best to have equal dispersion (Jo et al., 1997).

MDA is quite sensitive to unequal dispersion (Balcaen and Ooghe, 2006). Compared to MDA, LR and Optimal Estimation Theory of ANN, are better with dispersion but ANN require the least dispersion at $20 \%$ failed firms before it could recognize pattern (Boritz et al., 1995; Du Jardin, 2015). However, no tool can perform reasonably well at this level of dispersion i.e. 20:80 (Boritz et al., 1995). The best option is to use equally dispersed data as most studies do. Most of the review studies have data dispersion ranging between 50-50 and 60-40 (Figure 11) with nearly half using equally dispersed data (Table 2).

The sample size available for analysis can also influence the performance of a tool and should thus be given serious consideration before selecting a tool. At least three of the reviewed studies (Tseng and Hu, 2010; De Andrés et al. 2012; Zhou et al. 2014), and other studies (Haykin, 1994; Min and Lee, 2005; Shin et al., 2005; Ravi Kumar and Ravi, 2007) clearly indicated that ANNs and MDAs need a large training sample in order to reasonably recognize pattern and provide highly accurate classification. According to Haykin (1994), the minimum number of sample firms required to train an ANN network is ten times the weights in the network with an allowable error margin of $10 \%$, i.e. over 1000 sample firms will be required to properly train a standard ANN to make it fit for generalization. This is not too commonly implemented in many ANN studies (Shin et al., 2005) as is evident in this study (Figure 12). However, Lee et al (2005) were able to show that ANNs can still perform reasonably well (better than statistical models) with a small number of sample firms provided 'a target vector is available'. Like with ANN, a primary study (Tseng and Hu, 2010) and another study (Ravi Kumar and Ravi, 2007) have reported DT and LR to require a large data set to perform well.

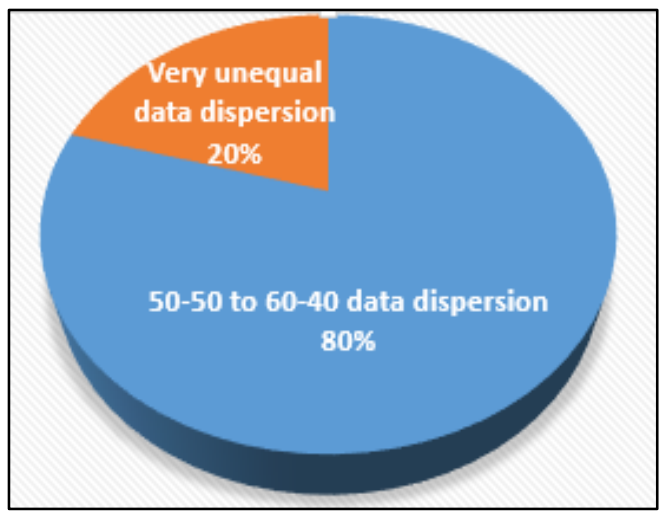

Figure 11: Proportion of studies that used equal or almost equal data dispersion

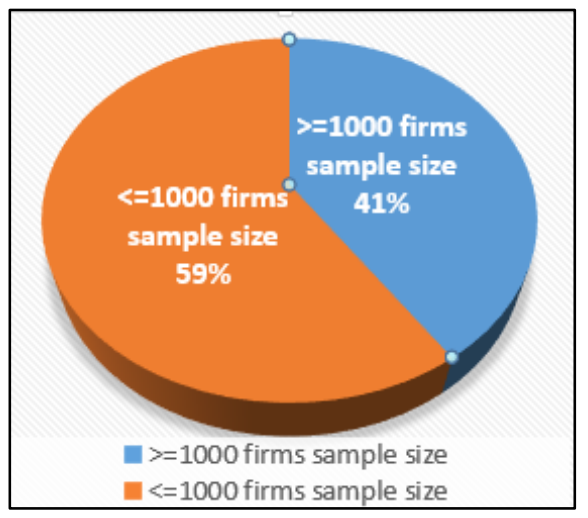

Figure 12: Proportion of studies that used less or more than the 1000 firms sample size for ANN

CBR, RS and SVM can handle small data size (Jo et al., 1997; Olmeda, and Fernández, 1997; Ravi Kumar and Ravi, 2007). Although Buta (1994) claimed that CBR's accuracy increases with increase in data size, Ravi Kumar and Ravi (2007) made it clear that it cannot handle very large data. At least four of the reviewed studies confirmed 
SVM's special ability to perform well with a small training dataset (Table 5), with Zhou et al. (2014) noting in their wide experiment that "most SVM-based models can still keep higher performance as the size of training samples decreases. It demonstrates that SVM models can keep good performance with small training samples, which has been proved in many other applications also" (p.248). In Yang et al.'s (2011) experiment, they showed that for their SVM, "the support vector number is 33 and $35 \ldots$ This shows that only 33 and 35 samples from the total of 120 samples are required to achieve the appropriate identification" (p.8340). In fact, Shin et al., (2005) did prove that SVM performs better and optimally with small training data sets as against a large one and fairs better than ANN only when a small data set is used to train both. This SVM's advantage is confirmed in older studies as well (e.g. Min and Lee, 2005; Shin et al., 2005; Ravi Kumar and Ravi, 2007).

\subsubsection{Variable Selection, Multicollinearity and Outliers}

Statistical tools, especially LR, are highly sensitive and reactive to multicollinearity hence an effective method of choosing non-collinear variables is normally employed for them (Edmister, 1972; Joy and Tollefson, 1975; Back et al., 1996; Lin and Piesse, 2004; Balcaen and Ooghe, 2006). Multicollinearity can easily lead to unstable performance and inaccurate results (Edmister, 1972; Joy and Tollefson, 1975; Balcaen and Ooghe, 2006). Before the emergence of AI tools, the most common variable selection method is the stepwise method because of its effectiveness in avoiding collinear variables (Altman, 1968; Back et al., 1996; Jo et al., 1997; Lin and Piesse, 2004). Its common use, over quarter of the studies used it, is usually to allow fair comparison with statistical tools.

The reviewed studies (Chen, 2011; Chen et al., 2011b; Yang et al., 2011; Liang et al., 2015) and other previous studies (Altman et al., 1994; Jo and Han, 1996; Chung et al., 2008) clearly indicate that AI tools, apart from CBR, are less sensitive to multicollinearity and can perform well with almost any variable selection method. CBR's performance decreases with increased number of variables (Chuang, 2013). On the other hand, some studies have claimed the higher the number of variables (usually when the multitude of variables available are used without selecting special ones), the better for ANN and GA (Chen, 2011; Chen et al., 2011b; Liang et al., 2015). In fact, Liang et al. (2015), who particularly investigated the effect of variable selection, concluded that "performing feature [variable] selection does not always improve the prediction performance" (p.289) of AI tools. However, Huang et al. (2012) feel removing irrelevant variables' can improve performance. Although Liang et al. (2015) found no best variable selection method in their study, they and Back et al. (1996) recommended GA as the best selection method for AI tools. Overall, it is not uncommon to use a decision rule generating AI tool to select variables for another AI tool as in some of the reviewed studies (Chen, 2011; Jeong et al., 2012; Zhou et al., 2014; Liang et al. 2015) and older studies (Wallrafen et al., 1996; Back et al., 1996; Ahn and Kim, 2009).

Although outliers can cause problems for any tool, LR has been particularly noted to be extremely sensitive to outliers in at least two of the reviewed studies (Kristóf and Virág, 2012; Tsai and Cheng 2012). Outlier effects are 
normally reduced by normalising variables by industry average (McKee 2000). Such normalization has however been found to reduce accuracy of models (Tam and Kiang, 1992; Jo et al., 1997).

\subsubsection{Types of Variables Applicable}

This criterion was not explicitly considered by the primary studies hence only the wider literature was used to discuss it. Although the vast majority of BPM studies use quantitative variables, usually in form of financial ratios, the need for qualitative/explanatory/managerial variables use, as noted in many studies, cannot be overemphasized (Argenti, 1980; Zavgren, 1985; Keasey and Watson, 1987; Abidali and Harris, 1995; Alaka et al., 2016 among others). MDAs can use only quantitative variables (Altman, 1968; Taffler, 1982; Odom and Sharda, 1990; Agarwa and Taffler, 2008; Chen, 2012; Bal et al., 2013 and more) while LR can use both (Ohlson, 1980; Keasey and Watson, 1987; Lin and Piesse, 2004; Cheng et al. 2006; Tseng and $\mathrm{Hu}, 2010$ ).

ANNs and SVMs can use mainly quantitative variables but can also use qualitative variables converted to quantitative variables using means such as the Likert scale (Cheng et al. 2006; Lin, 2009; StatSoft, 2014). All AI tools that yield the 'if... then,' decision rules for bankruptcy prediction, inclusive of RS, DT, CBR and GA, use qualitative variables and need quantitative variables to be converted to qualitative such as 'low, medium, high' etc. before they can be analyzed making them suitable for use of combined variables (Quinlan; 1986; Dimitras et al., 1999; Shin and Lee, 2002; Ravi Kumar and Ravi, 2007; Martin et al., 2012). The conversion is however not carried out by the AI and "involves dividing the original domain into subintervals which appropriately reflect theory and knowledge of the domain" (McKee, 2000, p. 165).

\subsection{Tools' Properties Related Criteria}

\subsubsection{Variables Relationship Capability and Assumptions Imposed by Tools}

Many independent variables used with BPM tools do not possess a linear relationship with the dependent variable (Keasey and Watson, 1991; Balcaen and Ooghe, 2006). Three of the reviewed studies (Du Jardin and Séverin, 2011; Divsalar et al., 2012; Du Jardin and Séverin, 2012) highlighted that MDA and LR require a linear and logistic relationship respectively between dependent and independent variables. This means important predictor variables with non-linear relationship to dependent variable will cause MDA to perform poorly. LR can solve logistic and non-linear problems (Tam and Kiang, 1992; Jackson and Wood, 2013). From this review, it appears all AI tools, except CBR (Chuang, 2013), can solve non-linear problems as identified by about a quarter of the reviewed studies (e.g. Divsalar et al., 2011; Du Jardin and Séverin, 2011, 2012; Chen et al., 2011b; Shie et al., 2012; Kasgari t al., 2013; Zhou et al., 2014; Yeh et al., 2014; among others). 
Du Jardin and Séverin (2011) and other studies (Coats and Fant 1993; Lin and Piesse, 2004; Balcaen and Ooghe, 2006; Chung et al., 2008; among others) have shown that statistical tools require data to satisfy certain restrictive assumptions for optimal performance. Some of these assumptions include multivariate normality of independent variables, equal group variance-covariance, groups are discrete and non-overlapping etc. (Ohlson, 1980 Joy and Tollefson, 1975; Altman, 1993; Balcaen and Ooghe, 2006). All these restrictive assumptions can barely be satisfied together by one data set hence are violated in many studies (Richardson and Davidson, 1984; Zavgren, 1985; Chung et al., 2008). Nonetheless LR is deemed relatively less demanding compared to MDA (Altman, 1993; Balcaen and Ooghe, 2006; Jackson and Wood, 2013). On the other hand, none of the reviewed studies noted any restrictive assumptions on data for AI tools. This is because they look to extract knowledge from training samples or directly compare a new case to cases in the case library (Coats and Fant 1993; Shin and Lee, 2002; Lin, 2009; Jackson and Wood, 2013).

\subsubsection{Sample Specificity/Overfitting Tendency and Generalizability of Tools}

The common use of stepwise variable selection method and mainly financial ratios as variables for statistical tools sometimes lead to a sample specific model where the model performs excellently on the samples used to build it but woefully on hold out samples thereby possessing low generalizability (Edmister, 1972; Lovell, 1983; Zavgren, 1985; Agarwal and Taffler, 2008). LR nonetheless has a relatively reasonable generalizability (Dreiseitl and OhnoMachado, 2002).

The equivalent of sample specificity in AI tools is called overfitting and is a common problem. There is also underfitting which is vice versa of overfitting. It is now a norm to avoid this problem (in statistical and AI tools) by testing models on a validation sample (and re-model if necessary) as indicated in most of the reviewed studies (Figure 13a). Over a third of the reviewed studies also pro-actively identified this problem early (Figure 13b) and considered it from the initial model development stage. Overfitting and underfitting are not necessarily caused by variable selection method or variable types in the case of AI tools. Apart from the case of CBR, it is generally known that the longer (shorter) the decision rules, the more the possibility of overfitting (underfitting) (Clark and Niblett, 1989; Brodley and Utgoff, 1995; Ravi Kumar and Ravi, 2007; Ren, 2012). CBRs tend not to overfit because they simply match a new case to one or more very similar cases in their library (Watson, 1997). CBR however has poor generalization but that is due to its poor accuracy (Ravi Kumar and Ravi, 2007). 

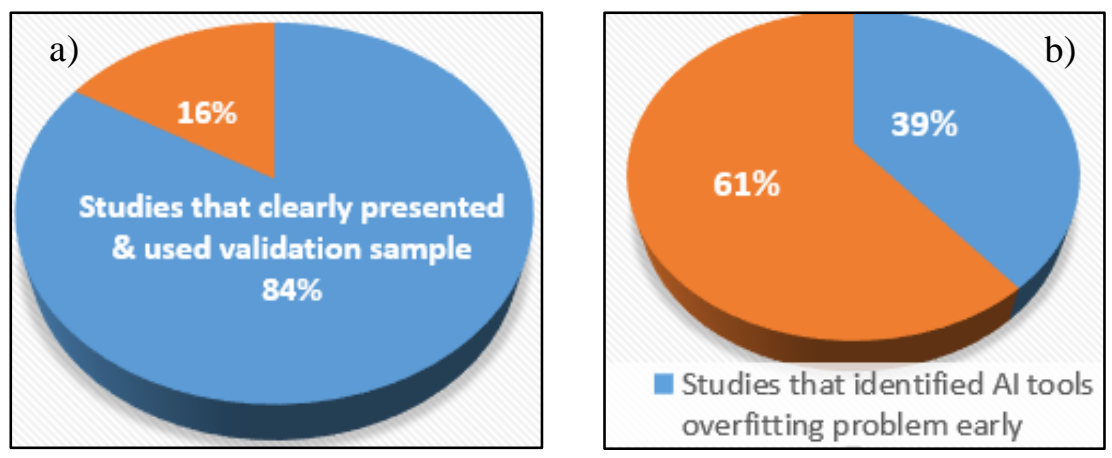

Figure 13: Proportion of studies that identified overfitting problem early and those that solved the problem using validation sample

Overfitting is a known problem of ANN and is as a result of overtraining the network (Min and Lee, 2005; Cheng et al. 2006; Ahn and Kim, 2009; Tseng and Hu, 2010; Jackson and Wood, 2013). Suggestions on how to construct more generalizable networks in ANN are given by Hertz et al. (1991). Overfitting (underfitting) in SVM is caused by a too large (small) upper bound value, usually denoted with ' $C$ ' (Min and Lee, 2005; Shin et al., 2005). Thus, finding the optimum number of training and optimum $C$ value for ANN and SVM respectively is key to their optimum performances. The notion that the structural risk minimization (SRM) used by SVM helps it to reduce the possibility of overfitting and increases generalization is not well proven according to Burges (1998). However, the tendency of overfitting in SVM is lower than in ANN and MDA (Cristianini and Shawe-Taylor, 2000; Kim, 2003; Shin et al., 2005).

\subsubsection{Model Development Time, Updatability and Integration Capability with other Tools}

Although the reviewed studies did not really touch on training times, past studies have noted that training AI tools, especially ANN and GA, can take a relatively longer time compared to statistical tools. This is because of the iterative process of finding the best parameters for AI tools (Jo and Han, 1996; Min and Lee, 2005; Ravi Kumar and Ravi, 2007). ANN architectures normally require many training cycles and GAs search for global optimum, while locating and negating local minima, make them (ANN and GA) take time for model development (Fletcher and Goss, 1993; Shin and Lee, 2002; Ravi Kumar and Ravi, 2007; Chung et al., 2008). For SVM, the polynomial function takes a long time but its RBF function is quicker (Kim, 2003; Huang et al., 2004). RS however does not take very long to train (Dimitras et al., 1999).

As noted in the reviewed studies, CBR and GA create the most updatable BPMs (Table7). CBR is easy to update and quite effective after an update since all it takes is to simply add new cases to its case library and prediction of a new case is done by finding the most similar cases(s) among all cases, old and new, in the library (Bryant, 1997; Ahn and Kim, 2009). An attempted update of a statistical BPM can lead to much reduced accuracy (Mensah, 1984; Charitou et al., 2004). ANNs can be adaptively updated with new samples since they are known to be robust on sample variations (Tam and Kiang, 1992; Altman, 1993; Zhang et al., 1999). However, if the situations of the 
new cases are significantly different for the ones used to build the model, then a new model must be developed (Chung et al., 2008). RS is particularly very sensitive to changes in data and can really be ineffective after an update with data that has serious sample variations (Ravi Kumar and Ravi, 2007)

AI tools are more flexible and allow integration with other tools better than statistical tools do. This is evident from the reviewed studies as more of the studies that used AI tools produced hybrids with them than those that used statistical tools (Figures 14a and b). The review clearly indicates that effective hybrids perform better than standalone tools (Tsai, 2014; Zhou et al., 2014; Iturriaga and Sanz, 2015), and "usually outperforms even the MLP [a type of ANN] and SVM procedure" (Iturriaga and Sanz 2015, p.2866). This is also confirmed in older studies (Jo and Han, 1996; Jeng et al., 1997; Ahn et al., 2000; Ahn and Kim, 2009). "However, these hybrid models consume more computational time" (Zhou et al. 2014, p.251) and "it is unknown which type of the prediction models by classifier ensembles and hybrid classifiers can perform better". (Tsai 2014, p.50)
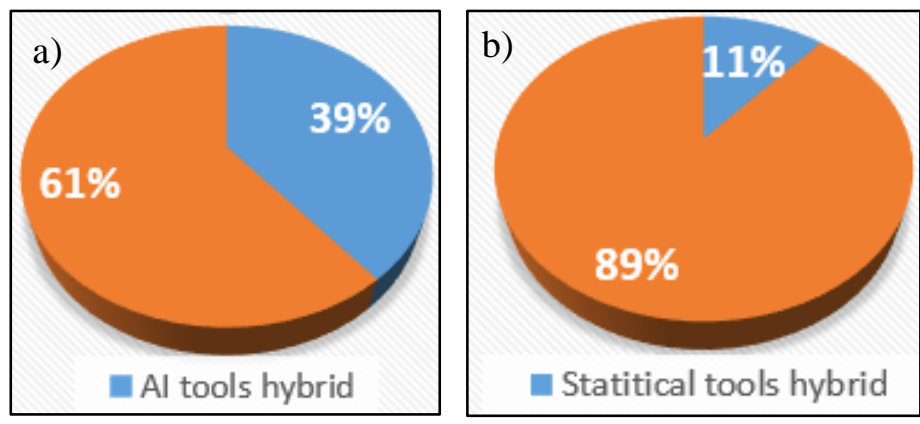

Figure 14: Proportion of studies that integrated AI or statistical tools to form a hybrid

\subsection{The Proposed Model}

Figure 15 presents a diagrammatic framework, gotten from the result of this review, which serves as a guideline for a BPM developer to select the right tool(s) that is best suited to available data and BPM preference criteria. Virtually all tools that are used for developing BPMs can successfully make predictions. However, some tools are more powerful in relation to certain criteria than others (see Table 6).

The framework clearly shows that to get the best performance from a BPM, the developing tool should be selected based on the output criteria preferences and the characteristics of data available. The framework is a very good starting point for any BPM developer and will ensure tools are not selected arbitrarily to the disadvantage of the developer. It will also ensure the final user of the BPM, having communicated his requirements to the model developer, gets the most appropriate BPM. For example, a BPM developer that considers accuracy as the highest preference because of his client's requirements, but has a very small dataset will not be wrongly choosing the highly accurate ANN for his model if this framework is used; SVM will be the right tool in such a circumstance. 
The implication of using this framework on practice is that it will allow tools to be used to the best of their strengths and encourage BPMs to be developed in a more customized way to customer/client requirements. This is better than to continue with the present trend of 'one size fits all' where a BPM is assumed to be good enough for the very different users/clients e.g. financiers, clients, owners, government agencies, auditors etc. It will also eliminate the time-wasting process of developing multiple BPMs with multiple tools in order to select the best after a series of test. The implication of this work on research is that it will guide researchers in selecting the best tool for their data and situation and help avoid the arbitrary selection of tools or selection simply based on popularity. It will also inform researchers on the need to use hybrid tools the more if the 'one size fits all' tool has to be achieved. It will hence invoke the development of new hybrid models.

Table 6: A tabular framework of tools' performance in relation to important BPMs criteria

\begin{tabular}{|c|c|c|c|c|c|c|c|c|}
\hline Tools category & \multicolumn{2}{|c|}{ Statistical } & \multicolumn{6}{|c|}{ AI tools } \\
\hline Important Criteria $\quad$ Tools & MDA & LR & ANN & SVM & RS & GA & DT & CBR \\
\hline Accuracy & Low & Mod. & V. High & V. High & High & High & Mod. & Low \\
\hline Result transparency & Low & High & Low & Low & High & High & High & High \\
\hline Can be Non-deterministic & No & No & No & No & Yes & Yes & Yes & Yes \\
\hline Ability to use small Samples size & Low & Low & Low & V. high & high & NR & low & high \\
\hline Data dispersion sensitivity & High & Normal & High & NR & NR & $\mathrm{NR}$ & NR & NR \\
\hline Suitable variable selection & SW & SW & Any & Any & Any & Any & Any & Any \\
\hline Multicollinearity Sensitivity & High & V. High & Low & Low & Low & Low & Low & Low \\
\hline Sensitivity to outlier & Mod. & High & Mod. & Mod. & Mod. & Mod. & Mod. & Mod. \\
\hline Variable type used & QN & Both & $\begin{array}{l}\text { QN } \\
\text { (both) }\end{array}$ & $\begin{array}{l}\text { QN } \\
\text { (both) }\end{array}$ & $\begin{array}{l}\text { QL } \\
\text { (both) }\end{array}$ & (both) & (both) & $\begin{array}{l}\mathrm{QL} \\
\text { (both) }\end{array}$ \\
\hline Variable relationship required & Linear & Logistic & Any & Any & Any & Any & Any & Linear \\
\hline $\begin{array}{l}\text { Other Assumptions to be } \\
\text { satisfied }\end{array}$ & Many & Some & None & None & None & None & None & None \\
\hline Overfitting possibility & Yes & Yes & Yes & Yes & Yes & Yes & Yes & No \\
\hline Updatability & Poor & Poor & $\mathrm{OK}$ & - & Poor & OK/Good & Poor & Good \\
\hline Ways to integrate to give hybrid & Few & Few & Many & Many & Many & Many & Many & Many \\
\hline Output Mode & Cut-off & Binary & Binary & Binary & DR & DR & DR & DR \\
\hline
\end{tabular}

Note: All rankings are relative. NR: Not Reported moderate
QN: Quantitative
QL: Qualitative
DR: Decision rules.
SW: Stepwise V.: Very Mod:

SW: Stepwise V.: Very Mod: 


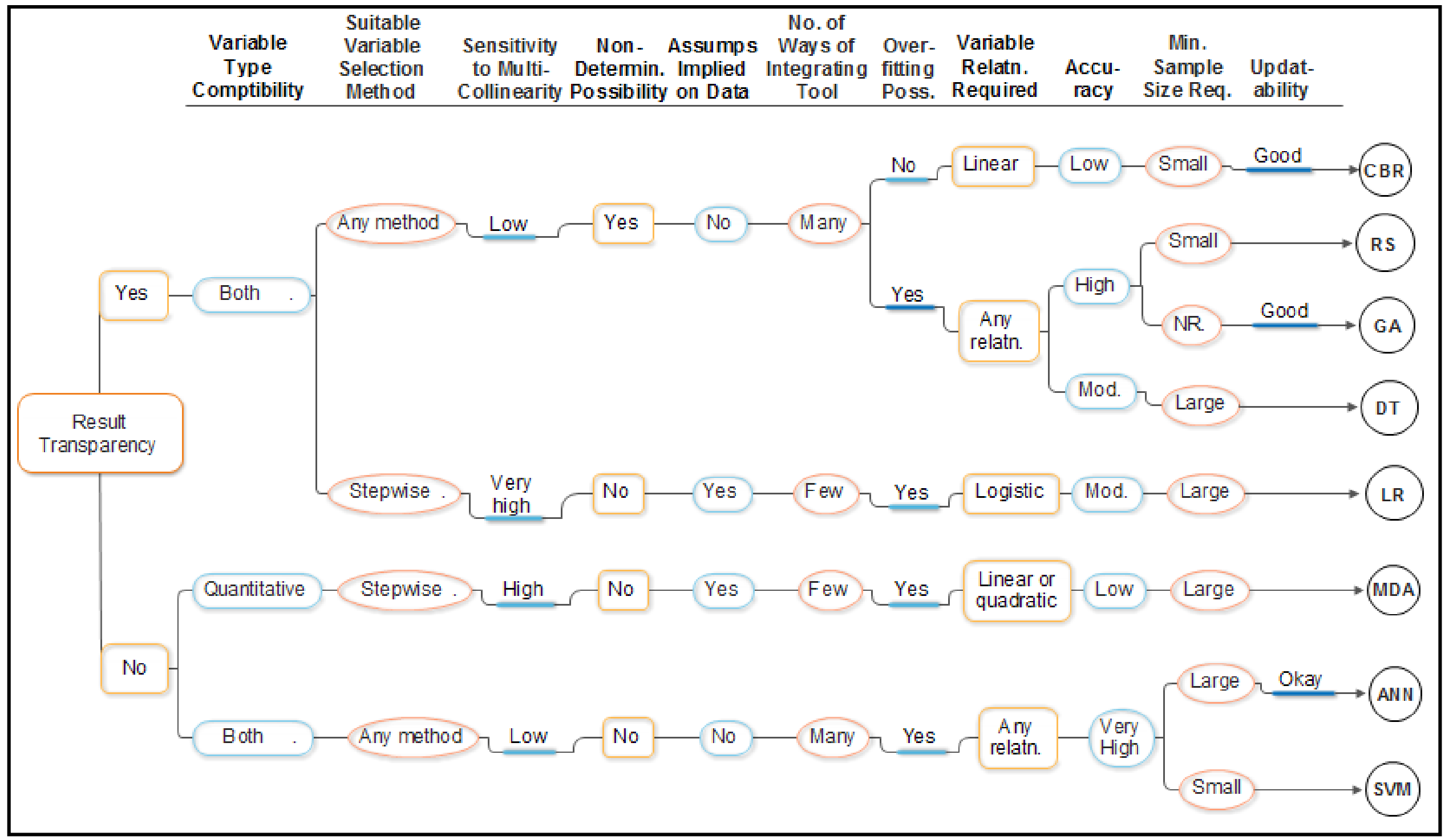

Figure 15: A framework for selection of the most suitable tools for various situations Determin: Deterministic Assumps: Assumptions No.: Number Poss: Possibility Min: Minimum Req: Required Mod.: Moderate

Relatn: Relationship 


\subsection{Conclusion}

The bankruptcy prediction research domain continues to evolve with many new models developed using various tools. Yet many of the tools are used with the wrong data conditions or for the wrong situation. This study used a systematic review, to reveal how eight popular and promising tools (MDA, LR, ANN, SVM, RS, CBR, DT and GA) perform with regard to various important criteria in the bankruptcy prediction models (BPM) study area. Overall, it can be concluded that there is no singular tool that is predominantly better than all other tools in relation to all identified criteria. It is however clear that each tool has its strengths and weaknesses that make it more suited to certain situations (i.e. data characteristics, developer aim, among others) than others. The framework presented in this study clearly provides a platform that allows a well-informed selection of tool(s) that can best fit the situation of a model developer.

The implication of this study is that BPM developers can now make an informed decision when selecting a tool for their model rather than make selection based on popularity or other unscholarly factors. In essence, tools will be more regularly selected based on their strength. Another implication is that BPMs with better performance with regards to end users' requirement will be more commonly developed. This is better than to continue with the present trend of 'one size fits all' where a BPM tool is assumed to be good enough for the very different users/clients (e.g. financiers, clients, owners, government agencies, auditors, among others) that need them. The framework in this study will also reduce the time-wasting process of developing many BPMs with different tools in order to select the best after a series of test; only the tools that best fit a developer's situation will be used and compared.

Future studies should consider possibilities of making ANN and SVM results interpretable since they appear to be the most accurate tools and satisfy a number of criteria for BPM. The very best overall model that will outperform all others in relation to all or most criteria, though not yet found, might come in the form of a hybrid of tools. Future research should thus, on one hand, explore various hybrids with the aim of developing the best hybrid that can achieve this fit. On the other hand, future studies should consider use of more sophisticated tools like Bart machine, extremely randomized trees, gradient boosting machine and extreme Gradient Boosting among others, as they might be the answer. As tools that can handle qualitative variables have been exposed in this study, future studies should consider the inclusion of qualitative variables in their BPM development as suggested in many studies (e.g. Argenti, 1980; Abidali and Harris, 1995; Alaka et al., 2017; among others). Further, future studies should look to combine qualitative and qualitative variables using these tools, with a view of developing better performing BPMs. Finally, future research should attempt to confirm/falsify the SVM tool's excellent capability to make predictions on small data size since it is generally known that the larger the data, the better. 


\section{References}

Abellán, J., and Mantas, C. J. (2014). Improving experimental studies about ensembles of classifiers for bankruptcy prediction and credit scoring. Expert Systems with Applications, 41 (8), pp. 3825-3830.

Abidali, A. F., and Harris, F. (1995). A methodology for predicting failure in the construction industry. Construction Management and Economics, 13 (3), pp. 189-196.

Agarwal, V., and Taffler, R. (2008). Comparing the performance of market-based and accounting-based bankruptcy prediction models. Journal of Banking and Finance, 32 (8), pp. 1541-1551.

Ahn, B. S., Cho, S. S., and Kim, C. Y. (2000). The integrated methodology of rough set theory and artificial neural network for business failure prediction. Expert Systems with Applications, 18 (2), pp. 65-74.

Ahn, H., and Kim, K. J. (2009). Bankruptcy prediction modeling with hybrid case-based reasoning and genetic algorithms approach. Applied Soft Computing, 9 (2), pp. 599-607.

Alaka, H, Oyedele, L, Toriola-Coker, O, Owolabi, H, Akinade, O, Bilal, M and Ajayi, S (2015) Methodological approach of construction businesses failure prediction studies: A review In: Raidén, A B and AboagyeNimo, E (Eds) Procs 31st Annual ARCOM Conference, 7-9 September 2015, Lincoln, UK, Association of Researchers in Construction Management, pp. 1291-1300.

Alaka, H. A., Oyedele, L. O., Owolabi, H. A., Ajayi, S. O., Bilal, M., \& Akinade, O. O. (2016). Methodological approach of construction business failure prediction studies: a review. Construction Management and Economics, 34(11), 808-842.

Alaka, H. A., Oyedele, L. O., Owolabi, H. A., Oyedele, A. A., Akinade, O. O., Bilal, M., \& Ajayi, S. O. (2017). Critical factors for insolvency prediction: towards a theoretical model for the construction industry. International Journal of Construction Management, 17(1), 25-49.

Altman E.I. (1968). Financial ratios discriminant analysis and the prediction of corporate bankruptcy, The Journal of Finance, 23 (4), pp. 589-609

Altman E. (1993). Corporate Financial Distress and Bankruptcy. 2nd ed. New York: John Wiley and Sons.

Altman, E. I., Marco, G., and Varetto, F. (1994). Corporate distress diagnosis: comparisons using linear discriminant analysis and neural networks (the Italian experience). Journal of banking and finance, 18 (3), 505-529

Appiah, K. O., Chizema, A., and Arthur, J. (2015). Predicting corporate failure: a systematic literature review of methodological issues. International Journal of Law and Management, 57 (5), pp. 461-485.

Argenti, J. (1980). Practical Corporate Planning. London: Allen and Unwin, 
Arieshanti, I., Purwananto, Y., Ramadhani, A., Nuha, M. U., and Ulinnuha, N. (2013). Comparative Study of Bankruptcy Prediction Models. TELKOMNIKA (Telecommunication Computing Electronics and Control), 11 (3), pp. 591-596.

Aziz, M. A. and Dar, H. A. (2006). Predicting corporate bankruptcy: where we stand? Corporate Governance, 6 (1), pp. 18-33.

Back, B., Laitinen, T., and Sere, K. (1996). Neural networks and genetic algorithms for bankruptcy predictions. Expert Systems with Applications, 11 (4), pp. 407-413.

Bal, J., Cheung, Y., and Wu, H. C. (2013). Entropy for business failure prediction: an improved prediction model for the construction industry. Advances in Decision Sciences, 2013 (2013), pp. 1-14.

Balcaen, S., and Ooghe, H. (2006). 35 years of studies on business failure: an overview of the classic statistical methodologies and their related problems. The British Accounting Review, 38 (1), pp. 63-93.

Beaver, W. H. (1966). Financial ratios as predictors of failure. Journal of Accounting Research, 4 (1966), pp. 71111.

Beaver, W. H., McNichols, M. F., \& Rhie, J. W. (2005). Have financial statements become less informative? Evidence from the ability of financial ratios to predict bankruptcy. Review of Accounting studies, 10 (1), pp. 93-122.

Bemš, J., Starý, O., Macaš, M., Žegklitz, J., and Pošík, P. (2015). Innovative default prediction approach. Expert Systems with Applications, 42 (17), pp. 6277-6285.

Boritz, J.E. and Kennedy, D. B. (1995). Effectiveness of neural network types for prediction of business failure. Expert Systems with Applications, 9 (4), pp. 503-512.

Boritz, J. E., Kennedy, D. B. and Albuquerque A.M. (1995). Predicting corporate failure using a neural network approach. Intelligent Systems in Accounting, Finance and Management, 4 (2), pp. 95-111.

Brodley, C. E., and Utgoff, P. E. (1995). Multivariate decision trees. Machine Learning, 19 (1), pp. 45-77.

Bryant, S. M. (1997). A case-based reasoning approach to bankruptcy prediction modeling. Intelligent Systems in Accounting, Finance and Management, 6 (3), pp. 195-214.

Burges, C. J. (1998). A tutorial on support vector machines for pattern recognition. Data Mining and Knowledge Discovery, 2 (2), pp. 121-167.

Buta, P. (1994). Mining for financial knowledge with CBR. Ai Expert, 9 (2), pp. 34-41.

Callejón, A. M., Casado, A. M., Fernández, M. A., and Peláez, J. I. (2013). A system of insolvency prediction for industrial companies using a financial alternative model with neural networks. International Journal of Computational Intelligence Systems, 6 (1), pp. 29-37.

Charitou, A., Neophytou, E., and Charalambous, C. (2004). Predicting corporate failure: empirical evidence for the UK. European Accounting Review, 13 (3), pp. 465-497.

Chen, H. L., Yang, B., Wang, G., Liu, J., Xu, X., Wang, S. J., and Liu, D. Y. (2011a). A novel bankruptcy prediction model based on an adaptive fuzzy k-nearest neighbor method. Knowledge-Based Systems, 24 (8), pp. 1348-1359. 
Chen, J. H. (2012). Developing SFNN models to predict financial distress of construction companies. Expert Systems with Applications, 39 (1), pp. 823-827.

Chen, M. Y. (2011). A hybrid model for business failure prediction-utilization of particle swarm optimization and support vector machines. Neural Network World, 21 (2), pp. 129-152.

Chen, N., Ribeiro, B., Vieira, A. S., Duarte, J., and Neves, J. C. (2011b). A genetic algorithm-based approach to cost-sensitive bankruptcy prediction. Expert Systems with Applications, 38 (10), pp. 12939-12945.

Cheng, C.B., Chen, C. L. and Fu, C.J. (2006). Financial distress prediction by a radial basis function network with logit analysis learning. Computers and Mathematics with Applications, 51 (3-4), pp. 579-588.

Cho, S., Hong, H., and Ha, B. C. (2010). A hybrid approach based on the combination of variable selection using decision trees and case-based reasoning using the Mahalanobis distance: For bankruptcy prediction. Expert Systems with Applications, 37 (4), pp. 3482-3488.

Chuang, C. L. (2013). Application of hybrid case-based reasoning for enhanced performance in bankruptcy prediction. Information Sciences, 236 (2013), pp. 174-185.

Chung, H.M.M., and Tam, K.Y. (1993). A Comparative Analysis of Inductive-Learning Algorithms. Intelligent Systems in Accounting, Finance and Management, 2 (1), pp. 3-18.

Chung, K. C., Tan, S. S. and Holdsworth, D. K. (2008). Insolvency prediction model using multivariate discriminant analysis and artificial neural network for the finance industry in New Zealand. International Journal of Business and Management, 39 (1), pp. 19-28.

Clark, P. and Niblett, T. (1989). The CN2 induction algorithm. Machine Learning, 3 (4), pp. 261-283.

Coats, P. K., and Fant, L. F. (1993). Recognizing financial distress patterns using a neural network tool. Financial Management, 22 (3), pp. 142-155.

Cristianini, N., and Shawe-Taylor, J. (2000). An Introduction to Support Vector Machines and other Kernel-Based Learning Methods. Cambridge; Cambridge university press.

De Andrés, J., Lorca, P., de Cos Juez, F. J., and Sánchez-Lasheras, F. (2011). Bankruptcy forecasting: A hybrid approach using Fuzzy c-means clustering and Multivariate Adaptive Regression Splines (MARS). Expert Systems with Applications, 38 (3), pp. 1866-1875.

De Andrés, J., Landajo, M., and Lorca, P. (2012). Bankruptcy prediction models based on multinorm analysis: An alternative to accounting ratios. Knowledge-Based Systems, 30, pp. 67-77.

Dimitras, A. I., Slowinski, R., Susmaga, R., and Zopounidis, C. (1999). Business failure prediction using rough sets. European Journal of Operational Research, 114 (2), 263-280.

Divsalar, M., Firouzabadi, A. K., Sadeghi, M., Behrooz, A. H., and Alavi, A. H. (2011). Towards the prediction of business failure via computational intelligence techniques. Expert Systems, 28 (3), pp.209-226.

Divsalar, M., Roodsaz, H., Vahdatinia, F., Norouzzadeh, G., and Behrooz, A. H. (2012). A Robust Data-Mining Approach to Bankruptcy Prediction. Journal of Forecasting, 31 (6), pp.504-523.

Dreiseitl, S., and Ohno-Machado, L. (2002). Logistic regression and artificial neural network classification models: a methodology review. Journal of biomedical informatics, 35 (5), pp. 352-359

Du Jardin, P. (2010). Predicting bankruptcy using neural networks and other classification methods: The influence of variable selection techniques on model accuracy. Neurocomputing, 73 (10), pp .2047-2060. 
Du Jardin, P. (2015). Bankruptcy prediction using terminal failure processes. European Journal of Operational Research, 242 (1), pp. 286-303.

Du Jardin, P., and Séverin, E. (2011). Predicting corporate bankruptcy using a self-organizing map: An empirical study to improve the forecasting horizon of a financial failure model. Decision Support Systems, 51 (3), pp. 701-711.

Du Jardin, P., and Séverin, E. (2012). Forecasting financial failure using a Kohonen map: A comparative study to improve model stability over time.European Journal of Operational Research, 221 (2), pp. 378-396.

Edmister, R. O. (1972). An empirical test of financial ratio analysis for small business failure prediction. Journal of Financial and Quantitative Analysis, 7 (02), pp. 1477-1493.

Edum-Fotwe, F., Price, A. and Thorpe, A. (1996) A review of financial ratio tools for predicting contractor insolvency. Construction Management and Economics, 14 (1996), pp. 189-198.

Fletcher, D. and Goss, E. (1993). Forecasting with neural networks: an application using bankruptcy data. Information and Management, 24 (3), pp. 159-167.

Gepp, A., Kumar, K., and Bhattacharya, S. (2010). Business failure prediction using decision trees. Journal of forecasting, 29 (6), pp. 536-555.

Gordini, N. (2014). A genetic algorithm approach for SMEs bankruptcy prediction: Empirical evidence from Italy. Expert Systems with Applications, 41 (14), pp. 6433-6445.

Greco, S., Matarazzo, B., and Slowinski, R. (2001). Rough sets theory for multicriteria decision analysis. European Journal of Operational Research, 129 (1), pp. 1-47.

Hafiz, A., Lukumon, O., Muhammad, B., Olugbenga, A., Hakeem, O., and Saheed, A. (2015, March). Bankruptcy Prediction of Construction Businesses: Towards a Big Data Analytics Approach. In Big Data Computing Service and Applications (BigDataService), 2015 IEEE First International Conference on (pp. 347-352). IEEE.

Haykin, S. (1994). Neural Networks: A Comprehensive Foundation. New York: Mc Millan.

Heo, J., and Yang, J. Y. (2014). AdaBoost based bankruptcy forecasting of Korean construction companies. Applied Soft Computing, 24, PP. 494-499.

Hertz, J., Krogh, A. and Palmer, R. (1991). Introduction to the Theory of Neural Computing. New York: Addison Wesley.

Higgins, J. P. (Ed.). (2008). Cochrane handbook for systematic reviews of interventions (Vol. 5). Chichester, England: Wiley-Blackwell.

Hillegeist, S. A., Keating, E. K., Cram, D. P., and Lundstedt, K. G. (2004). Assessing the probability of bankruptcy. Review of accounting studies, 9 (1), pp.5-34.

Ho, C. Y., McCarthy, P., Yang, Y., and Ye, X. (2013). Bankruptcy in the pulp and paper industry: market's reaction and prediction. Empirical Economics, 45 (3), pp. 1205-1232.

Huang, S. C., Tang, Y. C., Lee, C. W., and Chang, M. J. (2012). Kernel local Fisher discriminant analysis based manifold-regularized SVM model for financial distress predictions. Expert Systems with Applications, 39 (3), pp. 3855-3861. 
Huang, Z., Chen, H., Hsu, C. J., Chen, W. H., and Wu, S. (2004). Credit rating analysis with support vector machines and neural networks: a market comparative study. Decision Support Systems, 37 (4), pp. 543-558.

Iturriaga, F. J. L., and Sanz, I. P. (2015). Bankruptcy visualization and prediction using neural networks: A study of US commercial banks. Expert Systems with Applications, 42 (6), p. 2857-2869.

Jackson, R. H., and Wood, A. (2013). The performance of insolvency prediction and credit risk models in the UK: a comparative study. The British Accounting Review, 45 (3), pp. 183-202.

Jeng, B., Jeng, Y. M., and Liang, T. P. (1997). FILM: a fuzzy inductive learning method for automated knowledge acquisition. Decision Support Systems, 21 (2), pp. 61-73.

Jeong, C., Min, J. H., and Kim, M. S. (2012). A tuning method for the architecture of neural network models incorporating GAM and GA as applied to bankruptcy prediction. Expert Systems with Applications, 39 (3), pp. 3650-3658.

Jo, H., and Han, I. (1996). Integration of case-based forecasting, neural network, and discriminant analysis for bankruptcy prediction. Expert Systems with applications, 11 (4), pp. 415-422.

Jo, H., Han, I., and Lee, H. (1997). Bankruptcy prediction using case-based reasoning, neural networks, and discriminant analysis. Expert Systems with Applications, 13 (2), pp. 97-108.

Joy, O. M., and Tollefson, J. O. (1975). On the financial applications of discriminant analysis. Journal of Financial and Quantitative Analysis, 10 (5), pp. 723-739.

Kasgari, A. A., Divsalar, M., Javid, M. R., and Ebrahimian, S. J. (2013). Prediction of bankruptcy Iranian corporations through artificial neural network and Probit-based analyses. Neural Computing and Applications, 23 (3-4), pp. 927-936.

Keasey, K., and Watson, R. (1987). Non-financial symptoms and the prediction of small company failure: a test of Argenti's hypotheses. Journal of Business Finance and Accounting, 14 (3), pp. 335-354.

Keasey, K., and Watson, R. (1991). Financial distress prediction models: a review of their usefulness ${ }^{1}$. British journal of Management, 2 (2), pp. 89-102.

Khademolqorani, S., Zeinal Hamadani, A., and Mokhatab Rafiei, F. (2015). A Hybrid Analysis Approach to Improve Financial Distress Forecasting: Empirical Evidence from Iran. Mathematical Problems in Engineering, 2015.

Khan, K. S., Kunz, R., Kleijnen, J., and Antes, G. (2003). Five steps to conducting a systematic review. Journal of the Royal Society of Medicine, 96 (3), pp. 118-121.

Kim, K. J. (2003). Financial time series forecasting using support vector machines. Neurocomputing, 55 (1), pp. 307-319.

Kim, M. J., and Kang, D. K. (2010). Ensemble with neural networks for bankruptcy prediction. Expert Systems with Applications, 37 (4), pp. 3373-3379.

Kim, S. Y. (2011). Prediction of hotel bankruptcy using support vector machine, artificial neural network, logistic regression, and multivariate discriminant analysis. The Service Industries Journal, 31 (3), pp. 441-468.

Kolodner, J. (1993). Case-Based Reasoning. San Francisco, California: Morgan Kaufmann Publishers Inc.

Koyuncugil, A. S., and Ozgulbas, N. (2012). Financial early warning system model and data mining application for risk detection. Expert Systems with Applications, 39 (6), pp. 6238-6253. 
Kristóf, T., and Virág, M. (2012). Data reduction and univariate splitting-Do they together provide better corporate bankruptcy prediction?. Acta Oeconomica, 62 (2), pp. 205-228.

Langford, D., Iyagba, R. and Komba, D.M. (1993) Prediction of solvency in construction companies, Construction Management and Economics, 11 (1993), pp. 317-325

Lee, K., Booth, D., and Alam, P. (2005). A comparison of supervised and unsupervised neural networks in predicting bankruptcy of Korean firms. Expert Systems with Applications, 29 (1), pp. 1-16.

Lee, S., and Choi, W. S. (2013). A multi-industry bankruptcy prediction model using back-propagation neural network and multivariate discriminant analysis.Expert Systems with Applications, 40(8), 2941-2946.

Li, H., Lee, Y. C., Zhou, Y. C., and Sun, J. (2011). The random subspace binary logit (RSBL) model for bankruptcy prediction. Knowledge-Based Systems, 24 (8), pp. 1380-1388.

Liang, D., Tsai, C. F., and Wu, H. T. (2015). The effect of feature selection on financial distress prediction. Knowledge-Based Systems, 73, pp. 289-297.

Lin, F., Liang, D., and Chu, W. S. (2010). The role of non-financial features related to corporate governance in business crisis prediction. Journal of Marine Science and Technology, 18 (4), pp.504-513.

Lin, F. Y., and McClean, S. (2001). A data mining approach to the prediction of corporate failure. KnowledgeBased Systems, 14 (3), pp. 189-195.

Lin, L., and Piesse, J. (2004). Identification of corporate distress in UK industrials: a conditional probability analysis approach. Applied Financial Economics, 14 (2), pp. 73-82.

Lin, T. H. (2009). A cross model study of corporate financial distress prediction in Taiwan: multiple discriminant analysis, logit, probit and neural networks models. Neurocomputing, 72 (16), pp. 3507-3516.

Lovell, M.C. (1983). Data mining. Review of Economic Statistics 65 (1), pp. 1-12.

Martens, D., Van Gestel, T., De Backer, M., Haesen, R., Vanthienen, J., and Baesens, B. (2010). Credit rating prediction using ant colony optimization.Journal of the Operational Research Society, 61 (4), pp. 561-573.

Martin, A., Manjula, M., and Venkatesan, D. V. P. (2011). A business intelligence model to predict bankruptcy using financial domain ontology with association rule mining algorithm. International Journal of Computer Science Issues, 8 (3), pp. 1694-0814.

Martin, A., Balaji, S. and Venkatesan V.P. (2012). Effective prediction of bankruptcy based on the qualitative factors using FID3 algorithm. International Journal of Computer Applications (0975 - 8887), 43 (21), pp. 28-32.

Mason, R. J. and Harris, F. C. (1979). Predicting company failure in the construction industry. In: Proceedings of Institution of Civil Engineers, 01 May 1979, 66 (2), London: Thomas Telford, pp. 301-307.

Mensah, Y. M. (1984). An examination of the stationarity of multivariate bankruptcy prediction models: a methodological study. Journal of Accounting Research, 22 (1), pp. 380-395.

McKee, T. E. (2000). Developing a bankruptcy prediction model via rough sets theory. Intelligent Systems in Accounting, Finance and Management, 9 (3), pp. 159-173.

McKee, T. E. (2003). Rough sets bankruptcy prediction models versus auditor signalling rates. Journal of Forecasting, 22 (8), pp. 569-586. 
Min, J. H., and Lee, Y. C. (2005). Bankruptcy prediction using support vector machine with optimal choice of kernel function parameters. Expert Systems with Applications, 28 (4), pp. 603-614.

Min, S. H., Lee, J., and Han, I. (2006). Hybrid genetic algorithms and support vector machines for bankruptcy prediction. Expert systems with applications, 31 (3), pp. 652-660.

Nasir, M. L., John, R. I., Bennett, S. C., Russell, D. M., and Patel, A. (2000). Predicting corporate bankruptcy using artificial neural networks. Journal of Applied Accounting Research, 5 (3), pp. 30-52.

Odom, M. D., and Sharda, R. (1990). A neural network model for bankruptcy prediction. In: IJCNN International Joint Conference on Neural Networks. San Diego, California, 17-21 June 1990. IEEE, pp. 163-168.

Ohlson, J.A. (1980). Financial ratios and the probabilistic prediction of bankruptcy. Journal of Accounting Research, 18 (1) pp. 109-131.

Olmeda, I., and Fernández, E. (1997). Hybrid classifiers for financial multicriteria decision making: the case of bankruptcy prediction. Computational Economics, 10 (4), pp. 317-335.

Pawlak, Z. (1982). Rough sets. International Journal of Computer and Information Sciences, 11 (5), pp. 341-356.

Quinlan, J. R. (1986). Induction of decision trees. Machine Learning, 1 (1), pp. 81-106.

Quinlan, J. R. (1993). Programs for machine learning. Morgan Kaufmann Series in Machine Learning. San Mateo, CA.

Ravi Kumar, P., and Ravi, V. (2007). Bankruptcy prediction in banks and firms via statistical and intelligent techniques-A review. European Journal of Operational Research, 180 (1), pp. 1-28.

Ren, D. (2012). Application attributes reduction of rough set in power system for fault diagnosis. Journal of Convergence Information Technology, 7 (13), pp. 300-308

Richardson, F. M., and Davidson, L. F. (1984). On linear discrimination with accounting ratios. Journal of Business Finance and Accounting, 11 (4), pp. 511-525.

Schlosser, R. W. (2007). Appraising the quality of systematic reviews. Focus: Technical Briefs, (17), pp. 1-8.

Shi, G. (2013). Data Mining and Knowledge Discovery for Geoscientists. San Diego: Elsevier

Shie, F. S., Chen, M. Y., and Liu, Y. S. (2012). Prediction of corporate financial distress: an application of the America banking industry. Neural Computing and Applications, 21 (7), pp. 1687-1696.

Shin, K. S., and Lee, Y. J. (2002). A genetic algorithm application in bankruptcy prediction modeling. Expert Systems with Applications, 23 (3), pp. 321-328.

Shin, K. S., Lee, T. S., and Kim, H. J. (2005). An application of support vector machines in bankruptcy prediction model. Expert Systems with Applications, 28 (1), pp. 127-135.

Smith, V., Devane, D., Begley, C. M., and Clarke, M. (2011). Methodology in conducting a systematic review of systematic reviews of healthcare interventions. BMC medical research methodology, 11 (1), 15.

StatSoft (2014). Support Vector Machines $\quad$ (SVM) [online]. Available from: http://www.statsoft.com/Textbook/Support-Vector-Machines\#index [Accessed 26 September 2016]

Stenbacka, C. (2001). Qualitative research requires quality concepts of its own. Management Decision, 39 (7), pp. 551-556. 
Sun, J., Li, H., Huang, Q. H., and He, K. Y. (2014). Predicting financial distress and corporate failure: A review from the state-of-the-art definitions, modeling, sampling, and featuring approaches. Knowledge-Based Systems, 57, 41-56.

Taffler, R. J. (1982). Forecasting company failure in the UK using discriminant analysis and financial ratio data. Journal of the Royal Statistical Society. Series A (General), 342-358.

Taffler, R. J. (1983). The assessment of company solvency and performance using a statistical model. Accounting and Business Research, 13 (52), pp. 295-308.

Tam, K. Y., and Kiang, M. Y. (1992). Managerial applications of neural networks: the case of bank failure predictions. Management science, 38 (7), pp. 926-947.

Tranfield, D. R., Denyer, D., and Smart, P. (2003). Towards a methodology for developing evidence-informed management knowledge by means of systematic review. British journal of management, 14, pp. 207-222.

Trochim, W.M. and Donnelly, J.P. (2006). The Research Methods Knowledge Base, 3rd ed. Ohio: Atomic Dog Publishing.

Tsai, C. F. (2014). Combining cluster analysis with classifier ensembles to predict financial distress. Information Fusion, 16, pp. 46-58.

Tsai, C. F., and Cheng, K. C. (2012). Simple instance selection for bankruptcy prediction. Knowledge-Based Systems, 27 (2012), pp. 333-342.

Tsai, C. F., and Hsu, Y. F. (2013). A Meta-learning Framework for Bankruptcy Prediction. Journal of Forecasting, 32 (2), pp. 167-179.

Tsai, C. F., Hsu, Y. F., and Yen, D. C. (2014). A comparative study of classifier ensembles for bankruptcy prediction. Applied Soft Computing, 24, pp. 977-984.

Tseng, F. M., and Hu, Y. C. (2010). Comparing four bankruptcy prediction models: logit, quadratic interval logit, neural and fuzzy neural networks. Expert Systems with Applications, 37 (3), pp. 1846-1853.

Tserng, H. P., Chen, P. C., Huang, W. H., Lei, M. C., and Tran, Q. H. (2014). Prediction of default probability for construction firms using the logit model .Journal of Civil Engineering and Management, 20 (2), pp. 247255.

Vapnik, V. (1998). Statistical Learning Theory (Vol. 2). New York: Springer

Virág, M., and Nyitrai, T. (2014). Is there a trade-off between the predictive power and the interpretability of bankruptcy models? The case of the first Hungarian bankruptcy prediction model. Acta Oeconomica, 64 (4), pp. 419-440.

Wang, G., Ma, J., and Yang, S. (2014). An improved boosting based on feature selection for corporate bankruptcy prediction. Expert Systems with Applications, 41 (5), pp. 2353-2361.

Wallrafen, J., Protzel, P., and Popp, H. (1996). Genetically optimized neural network classifiers for bankruptcy prediction-an empirical study. In: Proceedings of the Twenty-Ninth Hawaii International Conference on System Sciences. Hawaii, USA, 3-6 Jan. 1996. Washington: IEEE Computer Society Press, cop., Vol. 2, pp. 419-426.

Watson, I. (1997). Applying case-based reasoning: techniques for enterprise systems. San Francisco, California: Morgan Kaufmann Publishers Inc. 
Won, C., Kim, J., and Bae, J. K. (2012). Using genetic algorithm based knowledge refinement model for dividend policy forecasting. Expert Systems with Applications, 39 (18), pp. 13472-13479.

Wilson, R. L., and Sharda, R. (1994). Bankruptcy prediction using neural networks. Decision Support Systems, 11(5), pp. 545-557.

Xiong, T., Wang, S., Mayers, A., and Monga, E. (2013). Personal bankruptcy prediction by mining credit card data. Expert Systems with Applications, 40 (2), pp. 665-676.

Xu, M., and Zhang, C. (2009). Bankruptcy prediction: the case of Japanese listed companies. Review of Accounting Studies, 14 (4), pp. 534-558.

Yang, Z., You, W., and Ji, G. (2011). Using partial least squares and support vector machines for bankruptcy prediction. Expert Systems with Applications, 38 (7), pp. 8336-8342.

Yeh, C. C., Chi, D. J., and Lin, Y. R. (2014). Going-concern prediction using hybrid random forests and rough set approach. Information Sciences, 254, pp. 98-110.

Yoon, J. S., and Kwon, Y. S. (2010). A practical approach to bankruptcy prediction for small businesses: Substituting the unavailable financial data for credit card sales information. Expert systems with Applications, 37 (5), pp. 3624-3629.

Yu, Q., Miche, Y., Séverin, E., and Lendasse, A. (2014). Bankruptcy prediction using extreme learning machine and financial expertise. Neurocomputing, 128, 296-302.

Zavgren, C. V. (1985). Assessing the vulnerability to failure of American industrial firms: a logistic analysis. Journal of Business Finance and Accounting, 12 (1), pp. 19-45.

Zhang, G., Hu, M.Y., Patuwo, E.B. and Indro, D.C. (1999). Artificial neural networks in bankruptcy prediction: general framework and cross-validation analysis. European Journal of Operational Research, 116 (1), pp. 16-32.

Zhou, L., Lai, K. K., and Yen, J. (2012). Empirical models based on features ranking techniques for corporate financial distress prediction. Computers and Mathematics with Applications, 64 (8), pp. 2484-2496.

Zhou, L., Lai, K. K., and Yen, J. (2014). Bankruptcy prediction using SVM models with a new approach to combine features selection and parameter optimisation. International Journal of Systems Science, 45 (3), pp. 241-253.

Zurada, J. M., Malinowski, A., and Cloete, I. (1994). Sensitivity analysis for minimization of input data dimension for feedforward neural network. In: IEEE International Symposium on Circuits and Systems, ISCAS'94, London, United Kingdom, 30 May - 2 June, 1994. Vol. 6, pp. 447-450. 